\title{
A 3D Numerical Approach to Assess the Temporal Evolution of Settlement Damage to Buildings on Cavities Subject to Weathering
}

\author{
Matteo O. Ciantia ${ }^{1,2} \cdot$ Riccardo Castellanza $^{3} \cdot$ Jose A. Fernandez-Merodo $^{4}$
}

Received: 26 June 2017 / Accepted: 27 March 2018 / Published online: 14 May 2018

(c) The Author(s) 2018

\begin{abstract}
The goal of this paper is to show how a recently developed advanced chemo-hydro-mechanical (CHM)-coupled constitutive and numerical model for soft rocks can be applied to predict the temporal evolution of settlement damage to buildings on cavities subject to weathering. In particular, a Building Damage Index $(B D I)$ and its evolution with time is proposed. The definition of the $B D I$ is inspired by the work of Boscardin and Cording (J Geotech Eng 115:1-21, 1989) and uses the surface differential settlements obtained by finite element $(F E)$ analyses to assess how far a building is from a non-acceptable service condition. By modelling the reactive transport of chemical species in 3D and using a coupled $C H M$ constitutive and numerical model, it is possible to simulate weathering scenarios and monitor the temporal evolution of surface settlements making the $B D I$ time dependent. This approach is applied to evaluate the damage evolution of two buildings lying on two anthropic caves in a calcarenite deposit belonging to the Calcarenite di Gravina Formation. Standard and advanced experimental tests are performed on the in situ material, and the results are used to calibrate the constitutive model. The soundness of both constitutive relationship and reactive transport solver is subsequently tested by simulating two laboratory-scale boundary value experiments. The first is a model footing test on dry and wet calcarenite, while the second is a small-scale pillar that, after the saturation-induced short-term water weakening, fails due to a long-term dissolution weathering process. Finally, both 2D and 3D coupled $F E$ analyses simulating different weathering scenarios and corresponding settlements affecting the buildings above the considered cavities are presented. Particular attention is placed on assessing the $B D I$ and its temporal evolution.
\end{abstract}

Keywords Finite element method $\cdot$ Building damage index BDI $\cdot$ Weathering $\cdot$ Hydro-chemo-mechanical coupling $\cdot$ Soft rocks $\cdot$ Sinkholes

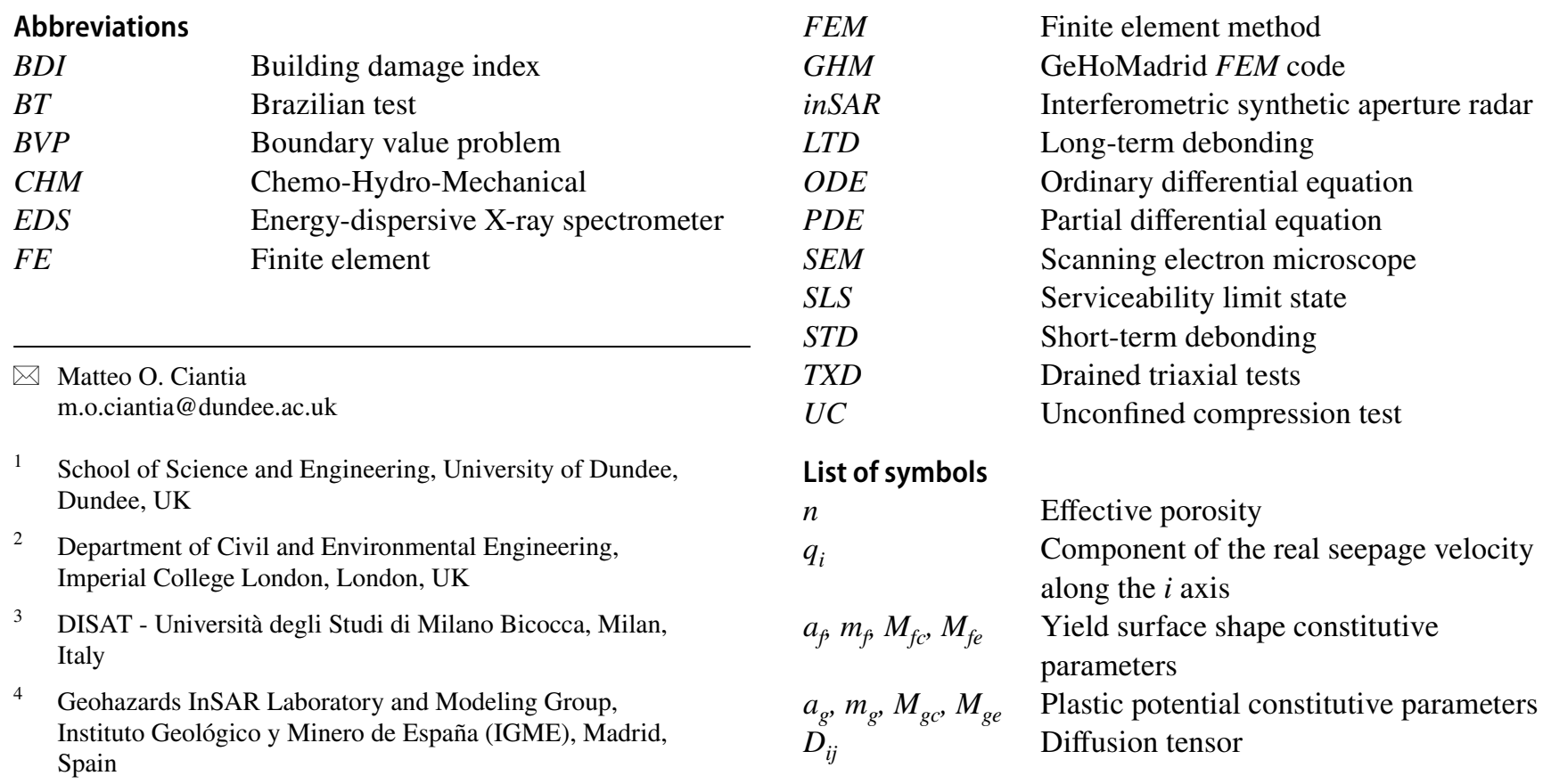




\begin{tabular}{|c|c|}
\hline$q_{\mathrm{S}}$ & $\begin{array}{l}\text { Volumetric flow rate of sink/source per } \\
\text { unit volume }\end{array}$ \\
\hline$C_{\mathrm{S}}^{k}$ & $\begin{array}{l}\text { Concentration associated with the } \\
\text { source or sink }\end{array}$ \\
\hline$\sum_{n=1}^{N} R_{n}$ & $\begin{array}{l}\text { Chemical sink/source term for } N \\
\text { chemical reactions }\end{array}$ \\
\hline$C^{k}$ & Concentration of the $k$ th compound \\
\hline [.] & Bulk fluid concentrations \\
\hline$K_{1}, K_{2}$ & Reaction rate constants \\
\hline$K_{\mathrm{gr}}$ & Oedometric stiffness granular state \\
\hline$\delta_{\mathrm{b}}$ & $\begin{array}{l}\text { Constitutive parameter related to the } \\
\text { extra stiffness caused by the bonds }\end{array}$ \\
\hline $\mathrm{CaCO}_{3(\mathrm{~s})}$ & $\begin{array}{l}\text { Calcium carbonate species in the solid } \\
\text { phase }\end{array}$ \\
\hline $\mathrm{H}_{3} \mathrm{O}_{(\mathrm{aq})}^{+}$ & Acid ions \\
\hline$\Delta M$ & Dissolved mass \\
\hline$f$ & Yield function \\
\hline$p^{\prime}$ & Mean effective stress \\
\hline$p_{\mathrm{s}}$ & Preconsolidation pressure \\
\hline$p_{t}$ & $\begin{array}{l}\text { Intersection of } f=0 \text { with the negative } p^{\prime} \\
\text { axis }\end{array}$ \\
\hline$p_{\mathrm{c}}$ & $\begin{array}{l}\text { Intersection of } f=0 \text { with the positive } p^{\prime} \\
\text { axis }\end{array}$ \\
\hline$p_{m}$ & $\begin{array}{l}\text { Bonding-induced increase in precon- } \\
\text { solidation pressure along } p^{\prime} \text { axis }\end{array}$ \\
\hline$p_{\mathrm{s} 0}, p_{t 0}, p_{m 0}$ & $\begin{array}{l}\text { Yield surface initial size constitutive } \\
\text { parameters }\end{array}$ \\
\hline$p_{\text {cell }}$ & Cell pressure in triaxial tests \\
\hline$q$ & Deviator stress \\
\hline$S_{\mathrm{r}}$ & Degree of saturation \\
\hline$S_{\mathrm{r}, \mathrm{cr}}$ & $\begin{array}{l}\text { Minimum } S_{\mathrm{r}} \text { necessary for all the depo- } \\
\text { sitional bonds to suspend }\end{array}$ \\
\hline$t$ & Time \\
\hline$Y$ & Weathering function \\
\hline$Y_{E}$ & Stiffness weathering function \\
\hline$\sigma_{\mathrm{a}}$ & Axial stress \\
\hline$\varepsilon_{\mathrm{a}}$ & Axial strain \\
\hline$\varepsilon_{\mathrm{h}}$ & Horizontal strain \\
\hline$\beta$ & Angular distortion \\
\hline$E$ & Young's modulus \\
\hline$E_{\mathrm{d}, 0}$ & $\begin{array}{l}\text { Young's modulus for the intact material } \\
\text { under dry conditions }\end{array}$ \\
\hline$E_{\mathrm{w}}$ & $\begin{array}{l}\text { Young's modulus for the under wet } \\
\text { conditions }\end{array}$ \\
\hline$E_{\mathrm{w}, 0}$ & $\begin{array}{l}\text { Young's modulus for the intact material } \\
\text { under wet conditions }\end{array}$ \\
\hline$\sigma_{\mathrm{cd}, 0}$ & $\begin{array}{l}\text { Initial uniaxial compression strength } \\
\text { under dry conditions }\end{array}$ \\
\hline$\sigma_{\mathrm{c}}$ & Uniaxial compression strength \\
\hline$\sigma_{\mathrm{cw}, 0}$ & $\begin{array}{l}\text { Initial uniaxial compression strength } \\
\text { under wet conditions }\end{array}$ \\
\hline
\end{tabular}

$\begin{array}{ll}\sigma_{\mathrm{cw}} & \begin{array}{l}\text { Uniaxial compression strength under } \\ \text { wet conditions }\end{array} \\ & \begin{array}{l}\text { Initial tensile strength under wet } \\ \text { conditions }\end{array} \\ \sigma_{\mathrm{tw}, 0} & \text { Tensile strength under wet conditions } \\ \sigma_{\mathrm{tw}} & \text { Constitutive parameter } \\ k & \text { Hardening constitutive parameters } \\ \rho_{\mathrm{s}}, \zeta_{\mathrm{s}}, \rho_{t}, \rho_{\mathrm{s}}, \zeta_{\mathrm{s}}, \zeta_{t} & \text { Stress tensor } \\ \sigma_{i j} & \text { Suspension process progress variable } \\ \xi_{\mathrm{sus}} & \text { Dissolution reaction progress variable } \\ \xi_{\mathrm{dis}} & \text { Corresponds to } \xi_{\mathrm{dis}} \text { when all diagenetic } \\ \xi_{\mathrm{dis}, \mathrm{cr}} & \text { bonds have been dissolved }\end{array}$

1 Introduction

Sinkholes, of both natural and anthropogenic origin, represent an important geological hazard in Europe and, worldwide and every year, cause significant property losses and causalities. Sinkhole formation is often the end result of complex physical hydraulic chemical phenomena (weathering) inducing continuous changes of the soils and rocks forming the earth crust causing a progressive reduction in mechanical properties including strength and deformability and variations of permeability. From an engineering perspective, the weathering-induced degradation of mechanical properties makes such phenomenon quite relevant as it generates deformation in the considered geotechnical systems and can compromise its mechanical stability in the worst case. For instance, leaching chemical-aggressive species can degrade the bond strength of cemented soils, causing settlements of structures founded on these materials (Lollino et al. 2013). In evaporites, the interaction of water with the gypsum pillars of an abandoned mine can transform this rock into a much weaker and compressible material, which can eventually collapse under the weight of the overburden (Castellanza et al. 2010). Also the simple saturation of a dry porous carbonate rock, limestone or other karstic formations leads to considerable changes in strength and stiffness that may cause large surface settlements unacceptable for the service life of existing structures, or even collapse in the form of sinkholes (Parise and Lollino 2011; Parise and Vennari 2017; Sowers 1996).

The substantial increase in sinkhole formation in the Apulian region in the last decades (Parise and Lollino 2011; Parise and Vennari 2017; Sowers 1996) has pushed the regional authorities to introduce new regulations regarding the procedures and requirements needed for risk assessment (L.R. 2002/19). In particular, in the annex introduced in 2006 specifically regarding the risk associated with underground mines (A.d.b. Puglia 2006), it is specified that for all existing structures in high-risk regions (PG3) two options are possible: the first is to fill the cavity with materials with 
similar mechanical properties of the host Calcarenite, the second is to perform numerical analyses to assess and predict the mechanical behaviour of the geosystem and propose eventual consolidation measures to fulfil required levels of serviceability and safety. Also a simple planning permission to change the use class of a construction now requires the application of one of these two options. When a building is resting on the top of an abandoned cavity (Fig. 1), the engineering question to be addressed is: how long will the building remain in serviceability conditions?

Despite considerable progress made in recent years in the study of the interactions between the soil (or rock) mass and the environment (including hydraulic, thermal and chemical coupling phenomena) (Alonso et al. 1990; Cekerevac and Laloui 2004; Della Vecchia and Romero 2013; Gajo et al. 2015; Gens 2010; Hueckel and Borsetto 1990; Jommi 2000;

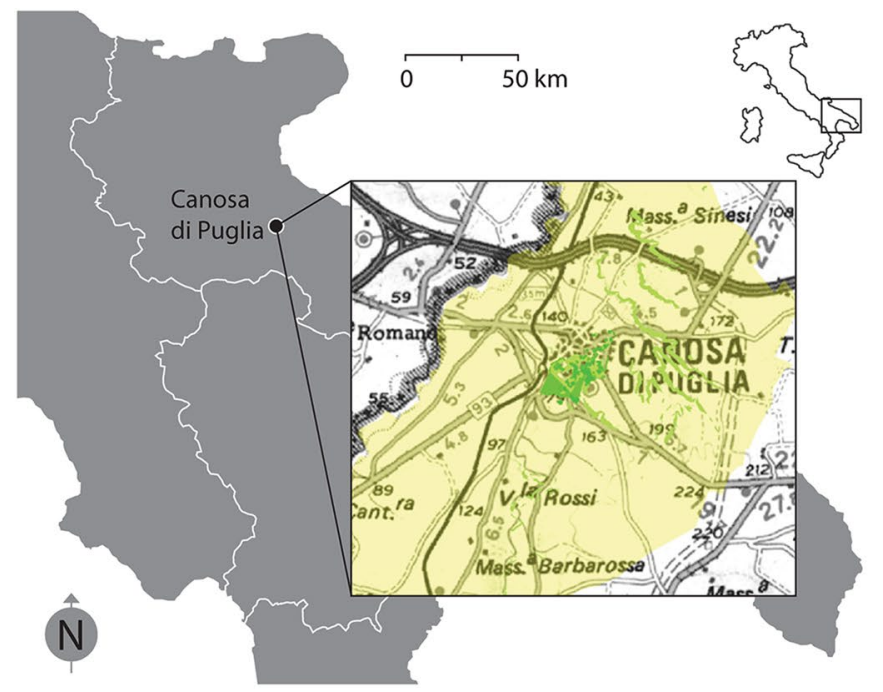

(a)

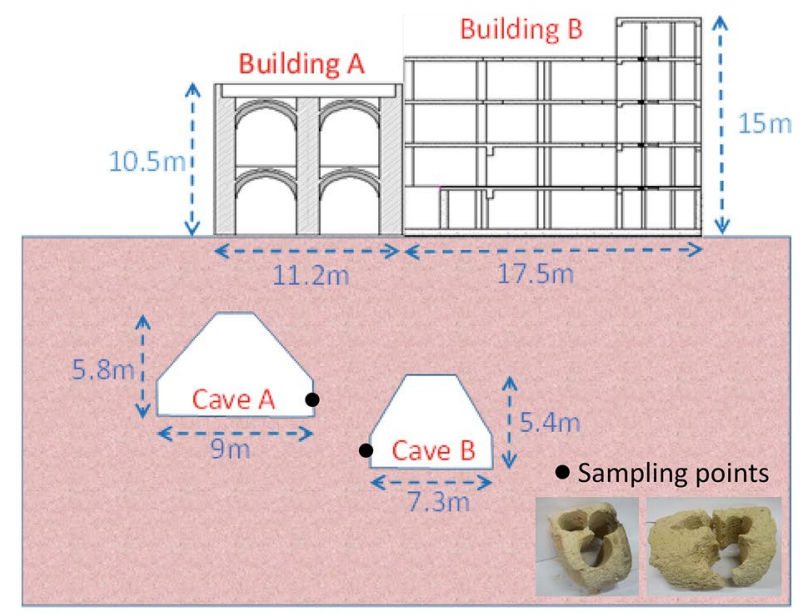

(c)
Uchaipichat and Khalili 2009), the application of advanced models to perform 3D numerical simulations to address such question is rare. In particular, chemo-hydro-mechanical ( $C H M$ )-coupled advanced numerical simulations are usually performed for 2D idealized problems to show the robustness of integration schemes or to simulate laboratory-scale boundary value problems (Fernandez-Merodo et al. 2007; Tamagnini et al. 2002; Tamagnini and Ciantia 2016).

In engineering practice, according to Eurocode 7 (EC7BSI 2004), it is necessary to demonstrate that building serviceability requirements can be met at the serviceability limit state $(S L S)$. Typically, building settlements (either gross or distortional) have to be smaller than limiting values which depend on the building type, ground type, and design approach. The choice of the analytical or numerical method used to assess the expected values of settlements is left to

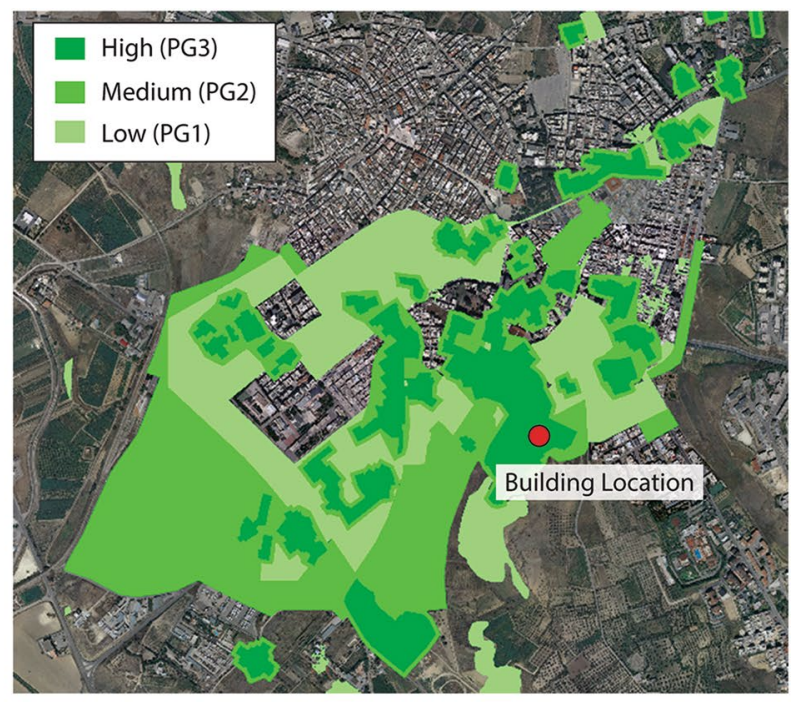

(b)

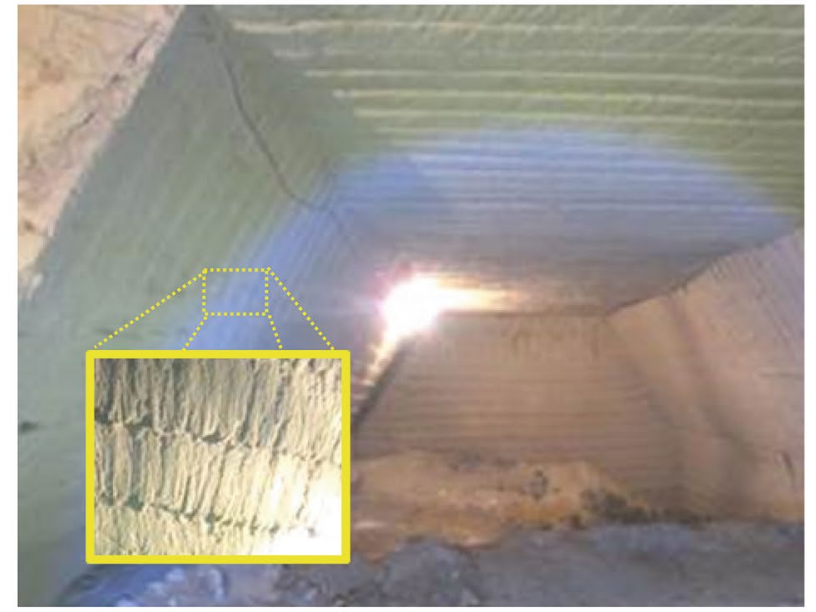

(d)

Fig. 1 a, b Map of Canosa di Puglia with the highlighted high-, medium- and low-risk zones and case study location (http://93.51.158.165/gis/ map_default.phtml), $\mathbf{c}$ section view of cave interacting with building; $\mathbf{d}$ picture of Cave A 
the engineer, and to this end, elastic methods, Winklerbased analyses and standard finite element $(F E)$ analyses may typically be used (Knappett and Craig 2012). However, the effect of weathering on serviceability of buildings is not contemplated by the design code, and in particular, no specific requirements for considering this are given in EC7. As shown by Conte et al. (2010), a simple way to model weathering in $F E$ analyses is to assume that a portion of the domain consists of a formation with lower mechanical characteristics. As described therein, the authors show how weathering changes stability of a weathered slope modelled in 2D. However, limit state analyses do not provide reliable deformation results as the deformations associated with $c-\phi$ analysis are not representative of reality.

This work proposes to exploit a $C H M$-coupled numerical model to study the serviceability conditions of buildings lying on cavities affected by environmental weathering by introducing a practical scalar index: the building damage index $(B D I)$. To answer to the question 'how long will the building remain in safety conditions', instead of assuming a strength profile and then performing a strength reduction analysis, hydro-chemical weathering scenarios are postulated and, by means of the reactive transport of contaminants, they are simulated. In this way, the spatial-temporal evolution of rock strength and stiffness will develop, and the surface settlements will induce damage to the structure until it is no longer safe. The method hence requires the use of both a coupled $C H M$ constitutive model and a $F E$ code which solves the hydro-mechanical problem and the transport of chemical species in porous medium. Small-scale coupled weathering experiments (needed to calibrate and validate the model) are then a prerequisite of fundamental importance for the proposed approach. In fact, in order to make reliable future predictions of the $B D I$, the model must first capture the temporal evolution of weathering at the laboratory scale.

In the following, after describing the method used to calculate the temporal evolution of the $B D I$, a brief overview of $3 \mathrm{D}$ contaminant transport modelling concepts is presented. Subsequently, the main elements of a recently developed advanced multiscale coupled $\mathrm{CHM}$ constitutive model (Ciantia and di Prisco 2015) used to describe the degradation of the soft carbonate rock induced by changes in degree of saturation (short-term debonding) and chemical dissolution (long-term debonding) (Ciantia et al. 2015a, b; Ciantia and Hueckel 2013) are described. Standard mechanical and advanced $C H M$ experimental tests on the calcarenite from site are also performed and used to calibrate the model. Experimental results of two boundary value experiments reproducing weathering scenarios at the laboratory scale are also presented and used for validation. Finally, 2D and 3D coupled $F E$ analyses simulating long-term effect of the weathering-induced settlements and the temporal evolution of $B D I$ of a building in Canosa di Puglia built on top of an abandoned cavity (Fig. 1) are presented. Attention is placed on comparing how the $B D I$ evolves with time for the 2 and 3D cases.

\section{A Time-Evolving Building Damage Index, $B D I(t)$}

Despite the fact that final stages of sinkhole formation in soft rocks is usually characterized by a rapid brittle type of global failure (Lollino and Andriani 2017), recent interferometric synthetic aperture radar (inSAR) measurements show that ground movements start to accumulate with time several months before the collapse (Chang and Hanssen 2014; Intrieri et al. 2015; Jones and Blom 2014; Nof et al. 2013). In the Marsala Panatletico 2011 sinkhole, signs of instability, such as open fractures and detachment blocks, were observed already 1 year prior to collapse (Fazio et al. 2017). Leucci et al. (2002) show that due to leakage of water into the ground can cause differential surface settlements causing the opening of fractures on the overlying buildings. The formation of cracks on buildings, implying ground level subsidence, months before the Gallipoli sinkhole of 2007 (Fig. 2) were also observed (Delle Rose 2007). These surface settlements, if identified within time, can avoid disasters and allow for actions for risk mitigation (De Giorgi and Leucci 2014).

All these observations lead to the need of introducing an approach able to estimate the level of safety of the buildings lying on rocks susceptible to weathering prior to the brittle
Fig. 2 Air and street views of sinkhole in Gallipoli occurred in 2007 (Polimeno 2007)
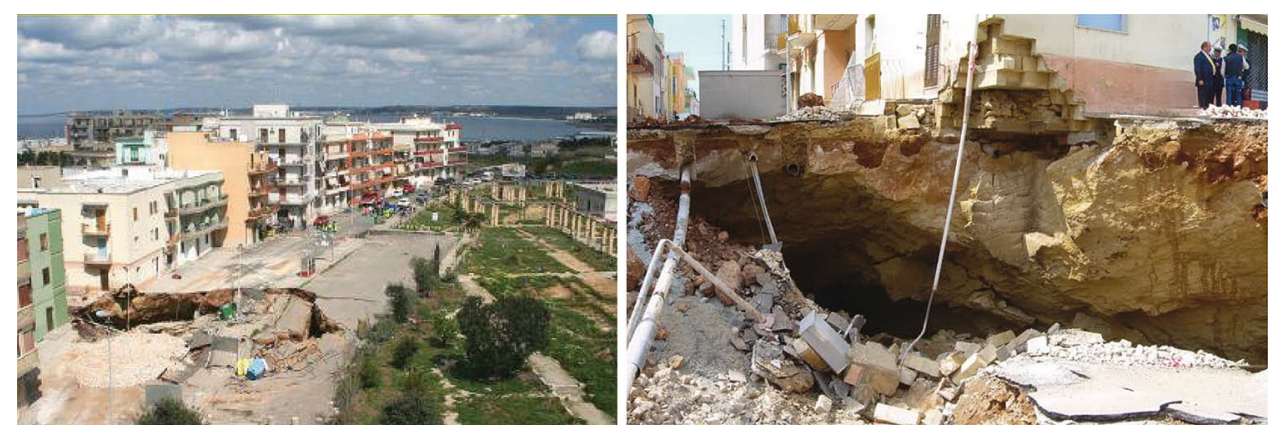
collapse of the geosystem, namely the building damage index, $B D I$. The formulation of the $B D I$ is inspired by the Eurocode 7 serviceability limit states (which are defined as states that correspond to conditions beyond which specified service requirements for a structure or structural member are no longer met) and the work of Boscardin and Cording (1989) that related the level of damage of buildings to surface settlements. Accordingly, the surface differential settlements obtained by $F E$ analyses are here used to assess how far a building is from a non-acceptable service condition. By modelling the reactive transport of chemical species and using a coupled CHM constitutive model where physical time is an intrinsic variable and rock damage is accounted for, it is possible to simulate weathering scenarios and monitor the temporal evolution of surface settlements and hence a $B D I$ function of time. The $B D I(t)$ is clearly strongly dependent on the weathering scenario assumed and on the constitutive model used to reproduce the mechanical behaviour. It gains in reliability as both the weathering mechanism reproduced, and the coupled constitutive models become more realistic. While advanced constitute relationships for calcarenites are now well established (Ciantia and di Prisco 2015), realistic hydrochemical weathering scenarios for underground cavities such as the ones reported by Ghabezloo and Pouya (2006) are harder to validate due to complexity of the processes involved. Nevertheless, in the absence of in situ experimental data on the hydro-chemical initial and boundary conditions, one may assume worst-case scenarios, that would in any case result more realistic than a classical stability analysis trough simultaneous homogenous strength reduction in all the whole domains (Castellanza et al. 2008). Temporal evolution of surface settlements are then used to determine the corresponding evolution of horizontal strain and angular distortion at the base of the building used to employ the well-known Boscardin and Cording abacus and to calculate $B D I(t)$ that, referring to Fig. 3, is defined as:

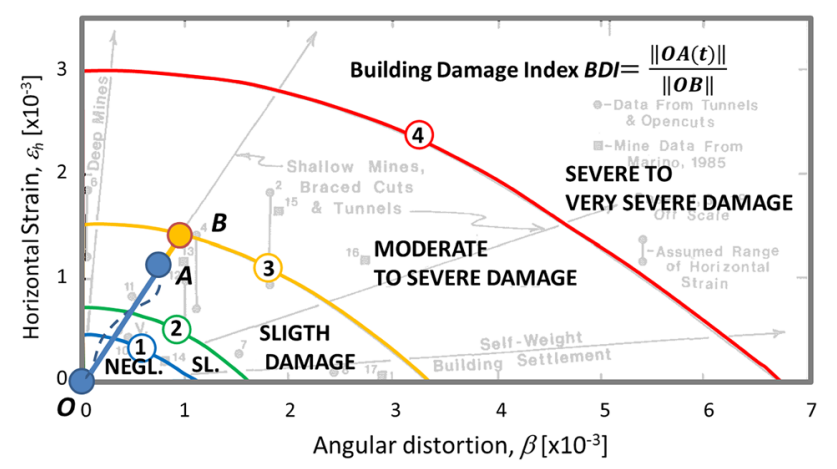

Fig. 3 Definition of the building damage index $(B D I)$ in Boscardin and Cording (1989) plot
$B D I(t)=\|O A(t)\| /\|O B\|$

where $\|O A(t)\|$ is the distance of the current state from the origin, while $\|O B\|$ is the distance from level of damage 3 to the origin obtained as an extension of $O A$. When the $B D I<1$, the settlement-induced damage on the building is slight or negligible, while if the $B D I>1$, the damage is moderate or severe.

In order to employ Boscardin and Cording's abacus to define the subsidence induced damage to the building and use Eq. (1), the following assumptions are required:

(i) the weathering effect causes surface settlements (subsidence) like the ones induced by tunnelling excavation,

(ii) the building stiffness is not considered as it is assumed not to affect the subsidence profiles, and the building displacement and deformations are assumed to coincide with the ones of the rock and

(iii) the building is assumed to comply with the Boscardin and Cording (1989) mechanical and geometrical assumptions.

The first assumption is deemed to be reasonable as the bell-shaped subsidence basin that characterizes sinkholes (Gutiérrez et al. 2008) has 2D sections which are very similar to the typical Gaussian-shaped transverse settlement observed in tunnelling excavation (Peck 1969). The latter two also limit the use of this approach to a certain typology of buildings, the one used to construct the abacus.

Despite the fact that this work uses a simplified method to define the level of structural damage, the methodological approach would remain unchanged also when running full soil-structure interaction simulations and can also be applied using other abaci or building damage criteria (e.g. Burland 1995; Burland and Wroth 1974; Franzius et al. 2006; Potts and Addenbrooke 1997; Son and Cording 2005).

The key aspect needed to introduce the $B D I(t)$ is to link the evolution of surface settlements to the hydro-chemical time-dependent weathering processes, and this is only possible if the mechanical behaviour is described by means of advanced coupled $C H M$ constitutive and numerical models.

\section{Constitutive and Numerical Modelling of Weathering in Soft Porous Carbonate Rocks}

The FEM code used in this work is the GeHoMadrid code $(G H M)$ developed by prof. M. Pastor and co-workers (Fernandez-Merodo et al. 2007). GHM is a non-commercial research code which solves the hydro-mechanical problem, following the $u-p_{\mathrm{w}}$ Biot coupled formulation (Zienkiewicz 
and Shiomi 1984), and hence the hydraulic problem (new seepage velocity, pore-pressure and saturation variations) and the mechanical response are solved simultaneously.

\subsection{Modelling the Transport of Chemical Species in Porous Medium}

From a mathematical point of view, the transport of a reactive compound is derived by fulfilling a mass balance equation for an elementary volume of the porous medium (see Zheng and Bennett 2002). The effects of chemical reactions on solute transport are generally included in the advection-diffusion equation through a chemical sink/source term, which can be formulated for each chemical compound of interest and added to the general advective-dispersive partial differential equation as follows:

$\frac{\partial\left(n C^{k}\right)}{\partial t}=\frac{\partial}{\partial x_{i}}\left(n D_{i j} \frac{\partial C^{k}}{\partial x_{j}}\right)-\frac{\partial}{\partial x_{i}}\left(n q_{i} C^{k}\right)+q_{\mathrm{S}} C_{\mathrm{S}}^{k}+\sum_{n=1}^{N} R_{n}$

where $C^{k}$ is the concentration of the $k$ th compound, $n$ is the effective porosity, $q_{i}$ is the component of the real seepage velocity along the $i$ axis, $D_{i j}$ is a diffusion tensor, incorporating the effects of dispersion, $q_{\mathrm{S}}$ is the volumetric flow rate of sink/source per unit volume and $C_{\mathrm{S}}^{k}$ is the concentration associated with the source or sink and $\sum_{n=1}^{N} R_{n}$ is the chemical sink/source term representing the rate of change in solute mass of a particular species due to $N$ chemical reactions. In this work, as in Fernandez-Merodo et al. (2007), it is assumed that the chemical reaction governing the dissolution of calcium carbonate forming the porous carbonate rock is given by the global equation:

$\mathrm{CaCO}_{3(\mathrm{~s})}+2 \mathrm{H}_{3} \mathrm{O}_{(\mathrm{aq})}^{+} \Leftrightarrow \mathrm{Ca}_{(\mathrm{aq})}^{2+}+3 \mathrm{H}_{2} \mathrm{O}_{(\mathrm{aq})}+\mathrm{CO}_{2(\mathrm{~g})}$ where the subindexes (g), (aq) and (s) refer to gas, aqueous and solid phases, respectively. The calcium carbonate species in the solid phase $\left(\mathrm{CaCO}_{3(\mathrm{~s})}\right)$ are assumed to be fixed, while the acid ions $\mathrm{H}_{3} \mathrm{O}_{(\mathrm{aq})}^{+}$are mobile. The transport equation for both species can be written as:

$$
\begin{aligned}
& \frac{\partial\left[\mathrm{H}_{3} \mathrm{O}^{+}\right]}{\partial t}=\frac{\partial}{\partial x_{i}}\left(D_{i j} \frac{\partial\left[\mathrm{H}_{3} \mathrm{O}^{+}\right]}{\partial x_{i}}\right)-\frac{\partial}{\partial x_{i}}\left(q_{i}\left[\mathrm{H}_{3} \mathrm{O}^{+}\right]\right)-K_{1}\left[\mathrm{CaCO}_{3}\right] \\
& \frac{\partial\left[\mathrm{CaCO}_{3}\right]}{\partial t}=-K_{2}\left[\mathrm{H}_{3} \mathrm{O}^{+}\right]
\end{aligned}
$$

where $K_{1}$ and $K_{2}$ are two constants characterizing the reaction rate and "[.]" indicates the amount of chemical concentration (i.e. solute mass per unit volume of water). The algorithm concerning the convection-diffusion reactive problem, developed for 2D problems by Fernandez-Merodo et al. (2007), was extended to the 3D case and tested here for the first time. Details of the numerical integration procedure are given in Appendix 1.

\subsection{Modelling the Mechanical Behaviour}

As shown in Fig. 4a where the first sketches of Prof. Nova are reported (Nova 1992, 1997), rock behaviour can be mathematically described by extending the strain-hardening plasticity framework used to model soils by increasing the size of the yield locus giving the material tensile strength. In particular, the intersections of the yield locus $(f=0)$ with the positive and negative p' axis are called $p_{c}=p_{\mathrm{s}}+p_{m}$, and $p_{t} ; p_{\mathrm{s}}$ acts as preconsolidation pressure, as it is for soils, and it is assumed to depend on both plastic volumetric and deviatoric strain rates. In contrast, $p_{t}$ and $p_{m}$ account for the effects of interparticle bonding. The existence of bonds therefore implies a nonzero tensile strength $\left(p_{t}>0\right)$ (Di Prisco et al. 1992) and an increase in the yield stress along radial loading paths. $p_{m}$

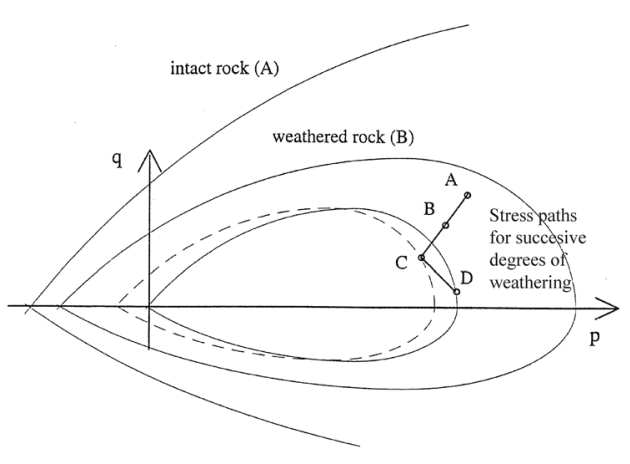

(a)

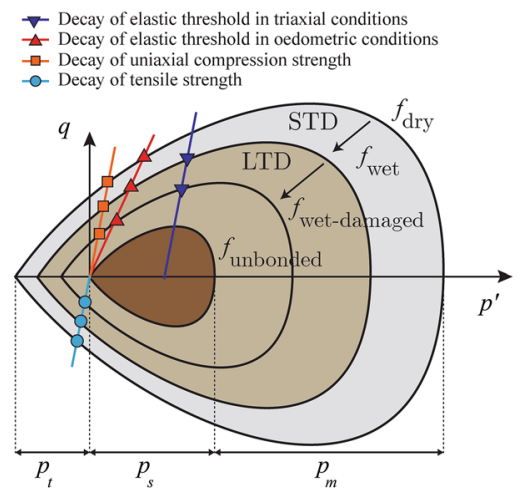

(b)

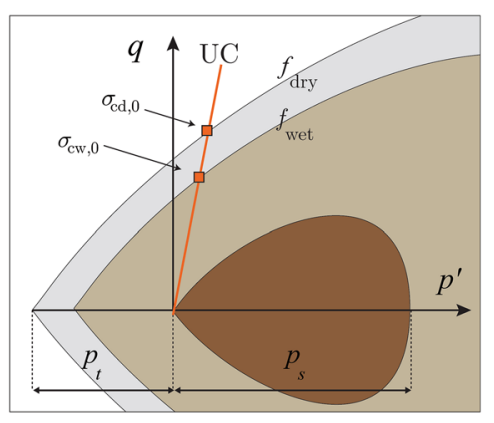

(c)

Fig. 4 a Concept of weathering for bonded geomaterials induced by shrinkage of the yield locus proposed by Nova (1992, 1997) and b, c current version of the weatheinrg model driven by the STD and LTD mechanisms (Ciantia and di Prisco 2015) 
corresponds to this increase in the case of isotropic compression path. Although $p_{t}$ and $p_{m}$ can generally be considered as two independent hardening variables, they are usually assumed to be linearly related, $p_{t}=k p_{m}$ (Lagioia and Nova 1995). To incorporate weathering, Nova and co-workers (Nova et al. 2003) introduced a scalar measure (going from 1 to 0 ) of weathering, namely the weathering function, $Y$. The latter described the shrinkage of the yield locus induced by nonmechanical processes (Lumb 1962) in a phenomenological way. Recently, micro- and macro-experimental evidence has shown the existence of two types of bonding, depositional and diagenetic, Ciantia et al. (2015a, b) and Ciantia and di Prisco (2015) redefined the weathering function by means of a multiscale approach (Fig. 4b, c). This allowed the weathering to be described using physical quantities namely the degree of saturation $\left(S_{\mathrm{r}}\right)$ and the normalized dissolved mass $\left(\xi_{\text {dis }}\right)$ of calcium carbonate (Fig. 5). A detailed description of the Nova model is given in Ciantia and di Prisco (2015), and hereafter the hardening laws:

$\dot{p}_{\mathrm{s}}=\rho_{\mathrm{s}} p_{\mathrm{s}}\left(\dot{\varepsilon}_{\mathrm{v}}^{p}+\zeta_{\mathrm{s}} \dot{\varepsilon}_{\mathrm{s}}^{p}\right)$

$\dot{p}_{t}=-\rho_{t} p_{t}\left(\dot{\varepsilon}_{\mathrm{v}}^{p}+\zeta_{t} \dot{\varepsilon}_{\mathrm{s}}^{p}\right)+\frac{p_{t}}{Y} \dot{Y}$

$\dot{Y}=\Xi \dot{\xi}_{\text {dis }}+\Sigma \dot{S}_{\mathrm{r}}$

$\dot{Y}_{E}=\Xi_{E} \dot{\xi}_{\text {dis }}+\Sigma_{E} \dot{S}_{\mathrm{r}}$

and the constitutive relationship:

$$
\begin{aligned}
\dot{\sigma}_{i j}= & D_{i j h k}^{e p} \dot{\varepsilon}_{h k}+\left(D(\Xi)_{i j}^{\mathrm{LTD}}+D\left(\Xi_{E}\right)_{i j}^{\mathrm{DAMAGE}-\mathrm{dia}}\right) \dot{\xi}_{\mathrm{dis}} \\
& +\left(D(\Sigma)_{i j}^{\mathrm{STD}}+D\left(\Sigma_{E}\right)_{i j}^{\text {DAMAGE-dep }}\right) \dot{S}_{r}
\end{aligned}
$$

are reported to ease the discussion on the numerical results. $Y$ and $Y_{E}$ represent the strength and stiffness weathering functions, which are the key functions that link the strength and stiffness evolution to the weathering driving variables, $S_{\mathrm{r}}$ and $\xi_{\text {dis }}$. In Appendix 2 the full expression of the weathering functions is reported.

\subsection{Chemo-Hydro-Mechanical FEM Coupling}

Despite that the mechanical part uses a Lagrangian approximation and the transport part an Eulerian one, the key point of the coupling is that both solvers use the same finite element mesh. Coupled formulation in GeHoMadrid uses for instance elements of kind T6P3 (triangle), Q8P4 (quadrilateral) in two dimensions or H8P4 (hexahedra), B20P4 (bricks) in three dimensions. The unknowns of the "transport solver' are the concentrations of $\mathrm{CaCO}_{3}$ and $\mathrm{H}_{3} \mathrm{O}^{+}$, Eq. (4). The coupling uses a "staggered" algorithm which works as follows: knowing the seepage velocity and the concentration value of $\mathrm{CaCO}_{3}$ and $\mathrm{H}_{3} \mathrm{O}^{+}$for each node at time $t$, the transport solver computes the new values at time $t+\mathrm{d} t$. The normalized dissolved mass, $\xi_{\text {dis }}$, is calculated using Eq. (26) in Appendix 2, and it is used as an input in the hydro-mechanical solver affecting the mechanical response (see Eq. 9). For a partially saturated sample, a water retention curve needs to be defined, which, knowing the pore pressure, allows the saturation degree $S_{\mathrm{r}}$, that governs the $S T D$ to be determined. As described in Fernandez-Merodo et al. (2007), since the two phenomena analysed have different time steps, the computations are arranged in such a way that there is an inner loop with small time steps for transport within the hydro-mechanical main loop, and several time steps are computed with the transport solver for each hydro-mechanical step. Another simplifying assumption can be made by not considering changes in seepage velocity; if the seepage velocity is constant, there is no change in pore pressure. The mechanical behaviour can be computed with a simple displacement formulation. For sake of simplicity, in this work the weathering path considered is as follows: during saturation, because the inundation phase is assumed to be rapid enough to prevent any dissolution, only the $S T D$ process is assumed to take place; consequently, $\xi_{\text {dis }}$ is constant, while $S_{\mathrm{r}}$ evolves from 0 to 1 . As detailed in Ciantia et al. (2015b), STD evolves for a limited range of degree of saturation. Once $S_{\mathrm{r}}>S_{\mathrm{r}, \mathrm{cr}}$ dissolution is assumed to start, and hence $L T D$ starts evolving with $\xi_{\text {dis }}$. Although features such as pressure solution (Rutter and Elliott 1976), opening of cracks and discontinuities (Lollino and Andriani 2017),
Fig. 5 Microscopic weakening processes: a saturation-induced short-term debonding of depositional bonds; $\mathbf{b}$, $\mathbf{c}$ dissolutiondriven long-term debonding and grain dissolution process (Ciantia et al. 2015a)

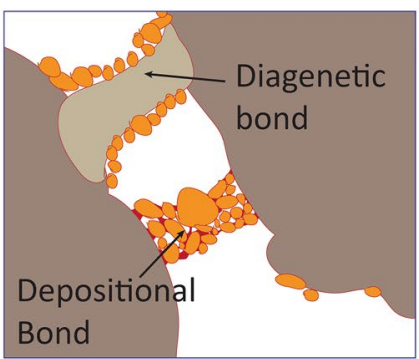

(a)

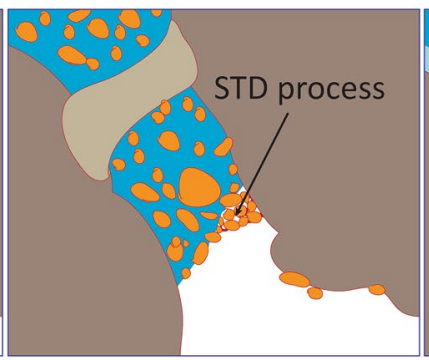

(b)

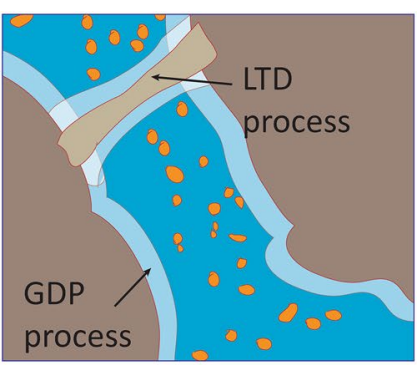

(c) 
chemical enhanced crack propagation (Hueckel et al. 2017) and strain localization cannot be captured by GHM and the adopted constitutive model, the definition and use of the $B D I(t)$ would remain unchanged even if more advanced numerical methods such as FDEM (Geomechanica Inc 2016) or P-FEM (Rodriguez et al. 2016) were to be used. Note that in the latter case a coupled constitutive relationship would still be required.

\section{Experimental Results and Model Calibration}

The material tested in the laboratory was retrieved from the man-made cave of the selected case study (represented in Fig. 1) that was excavated in a calcarenite deposit in the urban area of Canosa di Puglia. The calcarenite is characterized by a porosity of $59 \%$ and a unit weight in a dry condition of $11.1 \mathrm{kN} / \mathrm{m}^{3}$. The experimental tests performed to adequately characterize the soft rock and calibrate the constitutive model are:

(i) Thin sections, scanning electron microscope (SEM) imaging with punctual energy-dispersive $\mathrm{X}$-ray spectrometer $(E D S)$ measurements to identify the chemi- cal composition and the presence of depositional and diagenetic bonds (Fig. 6).

(ii) Uniaxial (UC), Brazilian (BT) and drained triaxial tests (TXD), on saturated samples to define the shape of the yield locus (Fig. 7).

(iii) $U C$ and $B T$ tests on dry $\left(S_{\mathrm{r}}=0\right)$, partially saturated $\left(0<S_{\mathrm{r}}<1\right)$ and saturated $\left(S_{\mathrm{r}} \sim 1\right)$ samples to calibrate the strength $(Y)$ and stiffness $\left(Y_{E}\right)$ weathering functions for the STD mechanism (Fig. 8).

(iv) The post-peak responses of the $U C$ and TXD tests are used to calibrate the mechanical hardening parameters, $\rho_{\mathrm{s}}, \rho_{t}$ and $\zeta_{t}$.

(v) $U C$ and $B T$ tests on saturated intact and artificially (with acid) pre-weathered samples to calibrate the strength and stiffness weathering function for the $L T D$ mechanism, are performed (Fig. 9).

Following Ciantia et al. (2015a), by analysing the thin sections with both a polarized light microscope and SEM, it was possible to identify the presence of both depositional and diagenetic bonds (Fig. 6). Punctual EDS analyses (Fig. 6) performed during SEM imaging of the thin sections confirm that both type of bonds are formed by $\mathrm{CaCO}_{3}$ microcrystals. While $U C$ and $B T$ tests are very useful to identify the yield locus at low confinement pressures, the TXD test

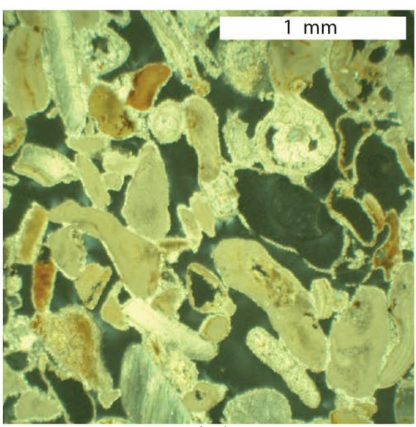

(a)

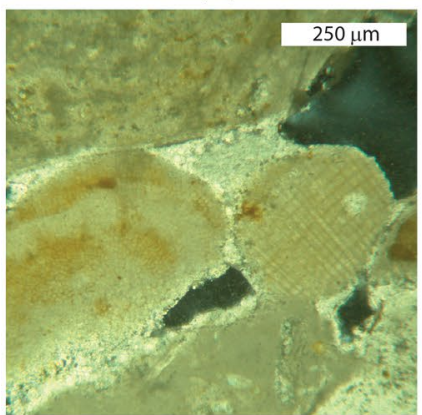

(b)

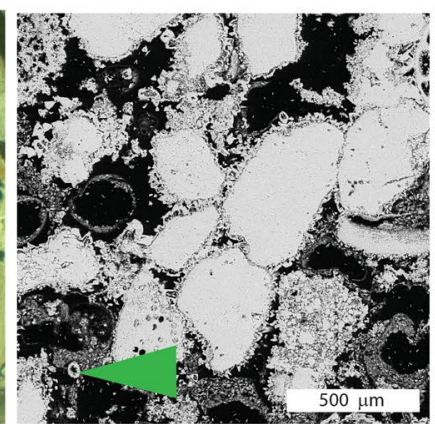

(c)

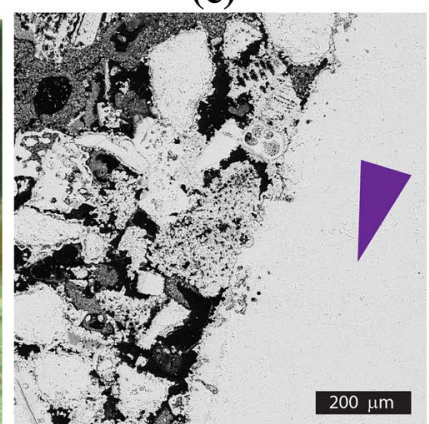

(d)

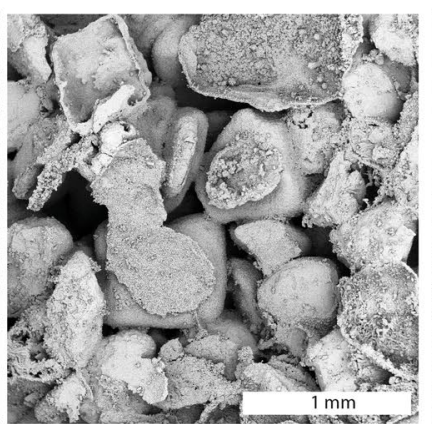

(e)

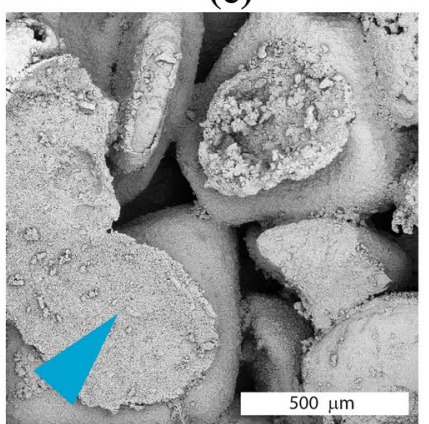

(f)

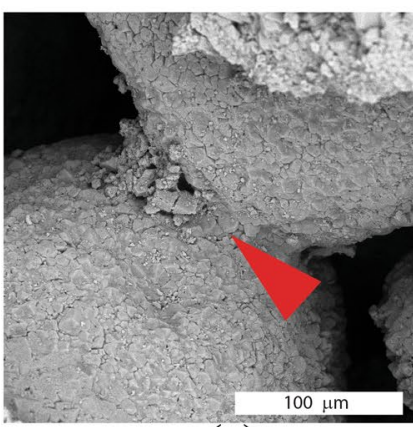

(g)

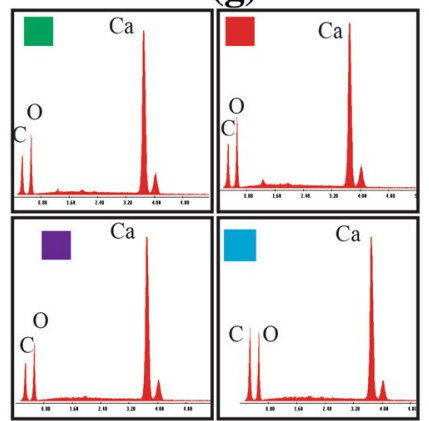

(h)

Fig. 6 Optical microscope $(\mathbf{a}, \mathbf{b})$ and SEM (c, d) images of thin sections of the in situ calcarenite. (e, f, $\mathbf{g})$ SEM images of 3D microstructure with different magnifications, and $\mathbf{h}$ corresponding punctual chemical analyses of the same calcarenite sample 


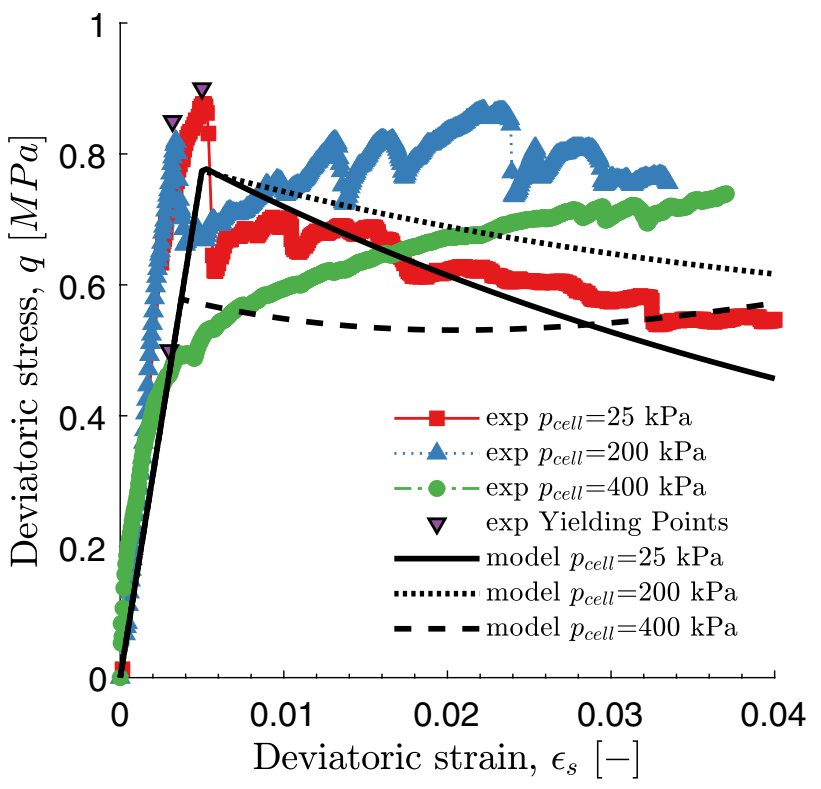

(a)

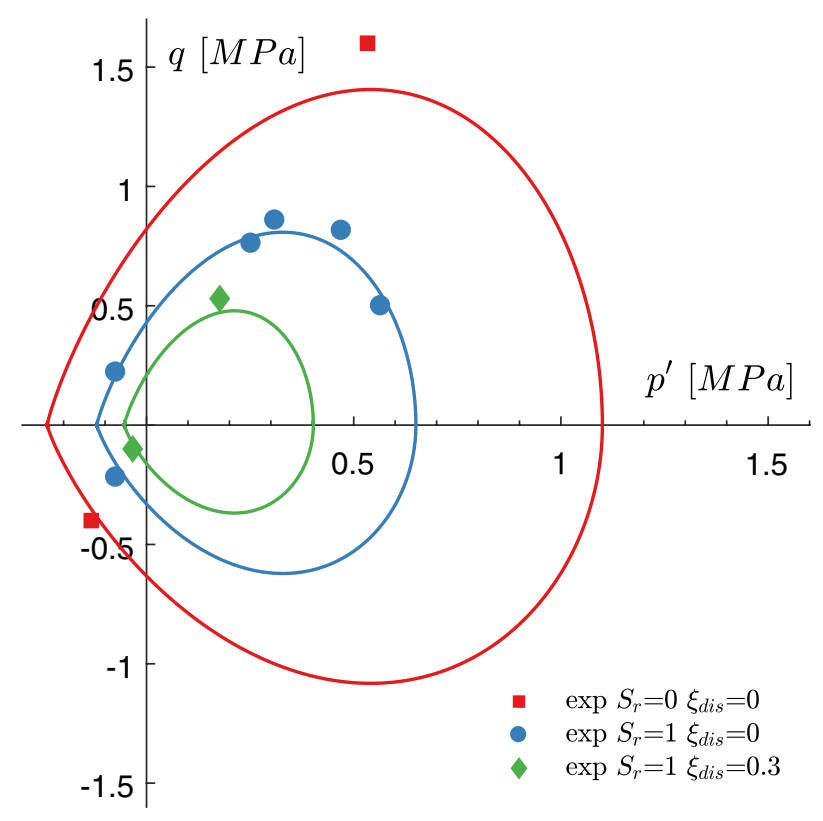

(b)

Fig. 7 a Results of the drained triaxial compression tests on saturated calcarenite at three different confining pressures and, $\mathbf{b}$ calibrated yield locus of dry $\left(S_{\mathrm{r}}=0\right)$, saturated $\left(S_{\mathrm{r}}=1\right)$ and Saturated weathered $\left(\xi_{\text {dis }}=0.3\right)$ calcarenite

are needed to identify the yield locus shape at high pressures (Fig. 7). In Fig. 8a typical axial stress-strain curves at different degrees of saturation are shown; the strength and stiffness reduction associated with higher saturation degrees are clearly visible. Figure $8 \mathrm{~b}$, c shows the normalized trend of $\sigma_{c}$ and $E$ versus $S_{\mathrm{r}}$. These results have been obtained by performing more than $40 U C$ tests on specimen with $38 \mathrm{~mm}$

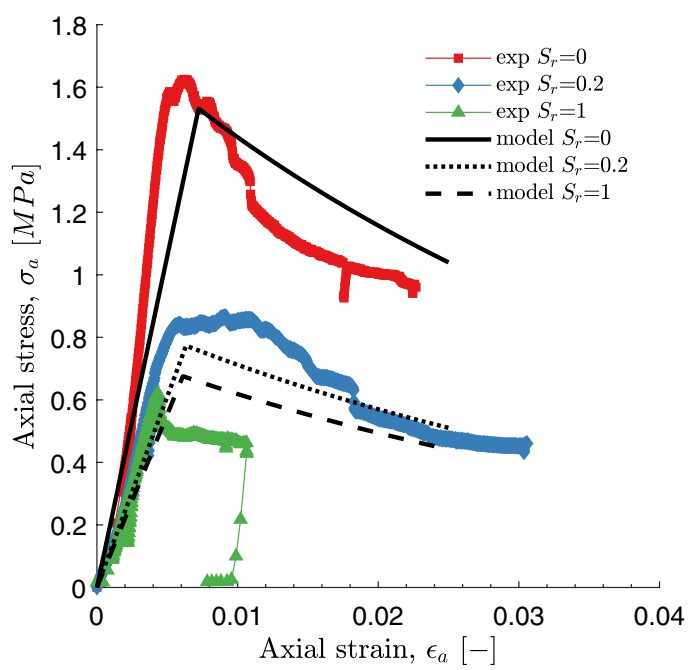

(a)

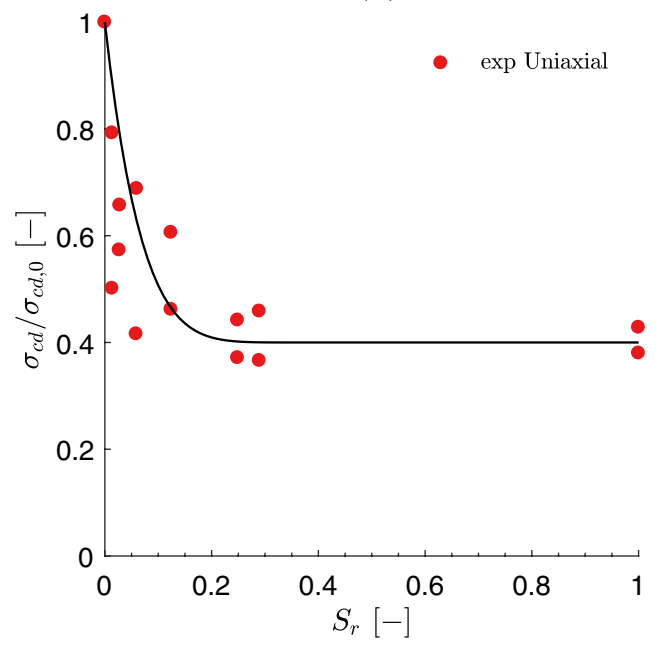

(b)

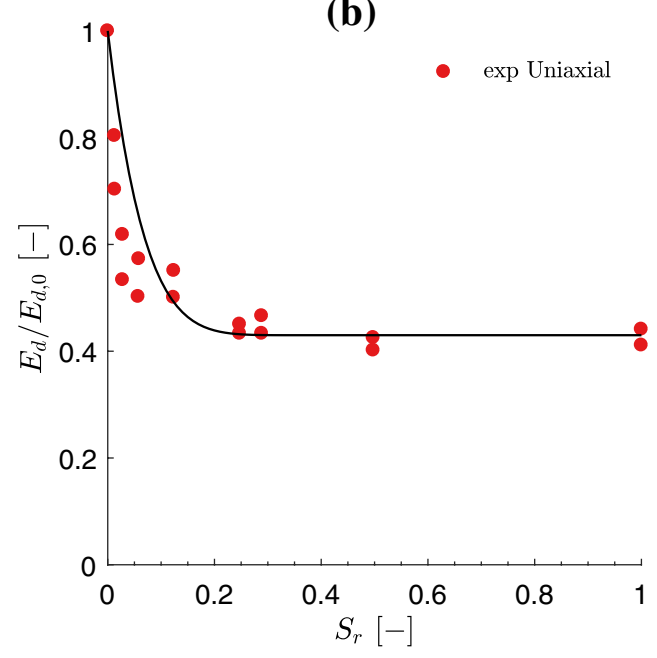

(c)

Fig. 8 STD - a results of the axial stress-strain curves of the uniaxial compression $(U C)$ tests on the in situ calcarenite sample at different degree of water saturation, $S_{\mathrm{r}} ; \mathbf{b}$ and $\mathbf{c}$ normalized reduction in UCS and Young modulus with $S_{\mathrm{r}}$ 


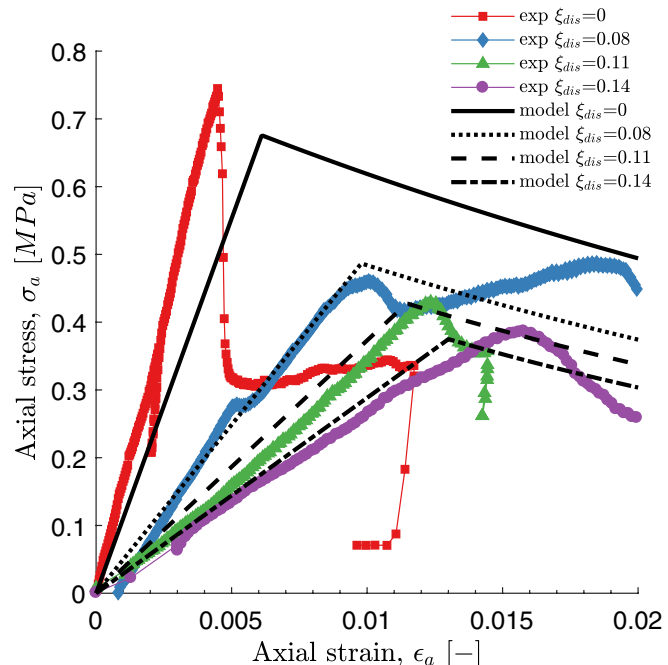

(a)

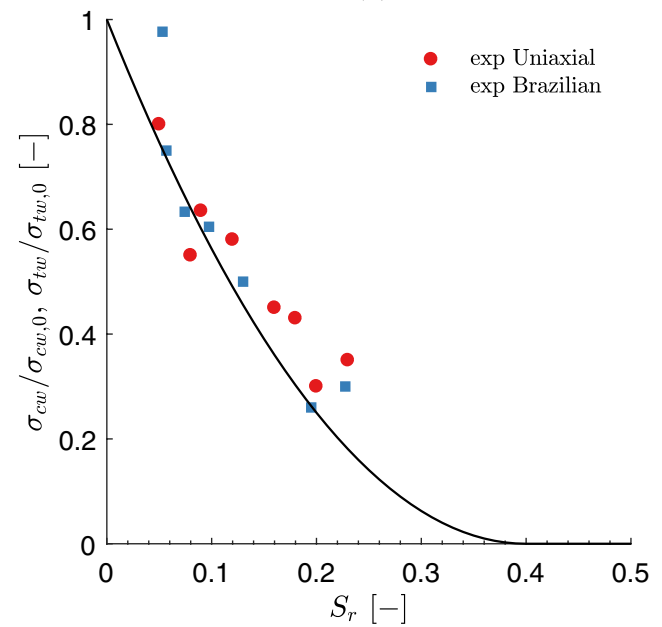

(b)

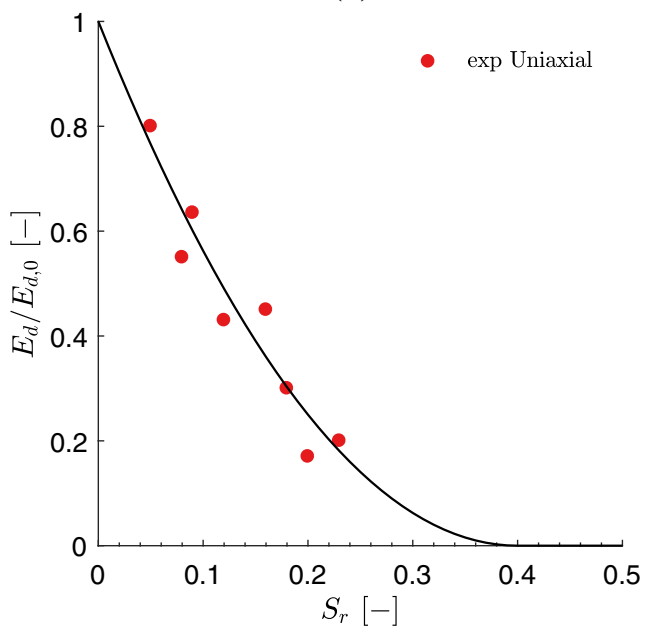

(c)

Fig. $9 L T D-$ a results of the axial stress-strain curves of $U C$ tests on the in situ calcarenite sample at different levels of accumulated dissolved mass index, $\xi_{\text {dis }} ; \mathbf{b}$ and $\mathbf{c}$ normalized reduction in UCS and Young modulus with $\xi_{\text {dis }}$ diameter using a displacement-controlled loading frame at $0.05 \mathrm{~mm} / \mathrm{min}$. The $L T D$ process has been analysed by means of a two-step experimental test: following the same procedure of Castellanza and Nova (2004), the samples were first weathered by means of an acid solution $(\mathrm{pH}=2.8)$ in order to accelerate the weathering process. In this initial phase, the dissolved mass $\Delta M$ is the measured variable and $\xi_{\text {dis }}$ is evaluated by means of Eq. (26). Subsequently, the samples are tested, and in Fig. 9b, c, the dependence of both strength and stiffness on $\xi_{\text {dis }}$ is illustrated, while in Fig. 9a, a selection of axial stress and strain curves at different values of $\xi_{\text {dis }}$ is shown. With the experimental tests presented, the constitutive model is calibrated, and the corresponding parameters and model fitting curves are reported in Tables 1, 2, 3, 4 and Figs. 7a, 8a, 9a.

\section{Model Validation at the Laboratory Scale}

As it was already mentioned, the reliability of the approach is strongly affected by various aspects, but the most critical is the correct numerical reproduction of weathering mechanism taking place. The capability of the model to capture rock weathering from a quantitative point of view at the laboratory scale is then a prerequisite. As the $C H M$ initial and boundary conditions in the laboratory can be controlled with reasonable accuracy, before using the approach as a predicting tool, the calibrated model should first capture the laboratory-scale response. For this reason, two BVP laboratory tests were performed and simulated with the already calibrated model. The first $(B V P \# 1)$ is a model footing test on dry and wet calcarenite, while the second ( $B V P \# 2)$ is a loaded small-scale pillar subject to both the STD and LTD weathering mechanisms. For this latter the experimental results are taken from Ciantia et al. (2015b). The calcarenite samples of the two $B V P$ 's were prepared from a Calcarenite di Gravina Formation block extracted few miles from the analysed cavity, hence have different initial strength conditions $\left(p_{m 0}\right)$, but the rest of the model parameters are the same.

\subsection{BVP\#1 Model Footing Tests on Dry and Wet Calcarenite}

$B V P \# 1$ is aimed to prove the capability of both the constitutive model and numerical code to properly simulate the short-term water-weakening effects (STD) on the bearing capacity of a small-scale footing. Two experimental tests were run, and the results are shown Figs. 10 and $11 \mathrm{a}$, while the $F E$ simulation results are reported in Fig. 11b. Both experiment and numerical simulation are performed controlling the vertical displacement of the rigid footing. It is worth noting the formation of a 
Table 1 Yield surface parameters and initial conditions

\begin{tabular}{llllllll}
\hline$a_{f}(-)$ & $m_{f}(-)$ & $M_{f c}(-)$ & $M_{f e}(-)$ & $k(-)$ & $p_{\mathrm{s} 0}(\mathrm{kPa})$ & $p_{m 0}(\mathrm{kPa})$ & $p_{t 0}(\mathrm{kPa})$ \\
\hline 0.8 & 0.99 & 1.8 & 1.4 & 0.27 & 200 & 450 & 121.5 \\
\hline
\end{tabular}

Table 2 Plastic potential and mechanical hardening/softening parameters

\begin{tabular}{llllllll}
\hline$a_{g}(-)$ & $m_{g}(-)$ & $M_{g c}(-)$ & $M_{g e}(-)$ & $\rho_{\mathrm{s}}(-)$ & $\zeta_{\mathrm{s}}(-)$ & $\rho_{t}(-)$ & $\zeta_{t}(-)$ \\
\hline $1 \mathrm{e}-6$ & 0.9 & 1.657 & 1.657 & 10 & -0.1 & 5 & 0 \\
\hline
\end{tabular}

Table 3 Weathering parameters

\begin{tabular}{llllll}
\hline$\xi_{\mathrm{dis}, \mathrm{cr}}(-)$ & $S_{\mathrm{r}, \mathrm{cr}}(-)$ & $\sigma_{\mathrm{cd}, 0}(\mathrm{kPa})$ & $\sigma_{\mathrm{cw}, 0}(\mathrm{kPa})$ & $E_{\mathrm{d}, 0}(\mathrm{MPa})$ & $E_{\mathrm{w}, 0}(\mathrm{MPa})$ \\
\hline 0.4 & 0.25 & $1600 \pm 100$ & $740 \pm 100$ & $315.0 \pm 100$ & $150.0 \pm 50$ \\
\hline
\end{tabular}

Table 4 Elastic parameters

\begin{tabular}{llll}
\hline$K_{\text {gr }}(\mathrm{MPa})$ & $\nu(-)$ & $p_{\mathrm{r}}(\mathrm{MPa})$ & $\delta_{\mathrm{b}}(-)$ \\
\hline $45 \pm 5$ & $0.09 \pm 0.02$ & 1000 & $5 \pm 1$ \\
\hline
\end{tabular}

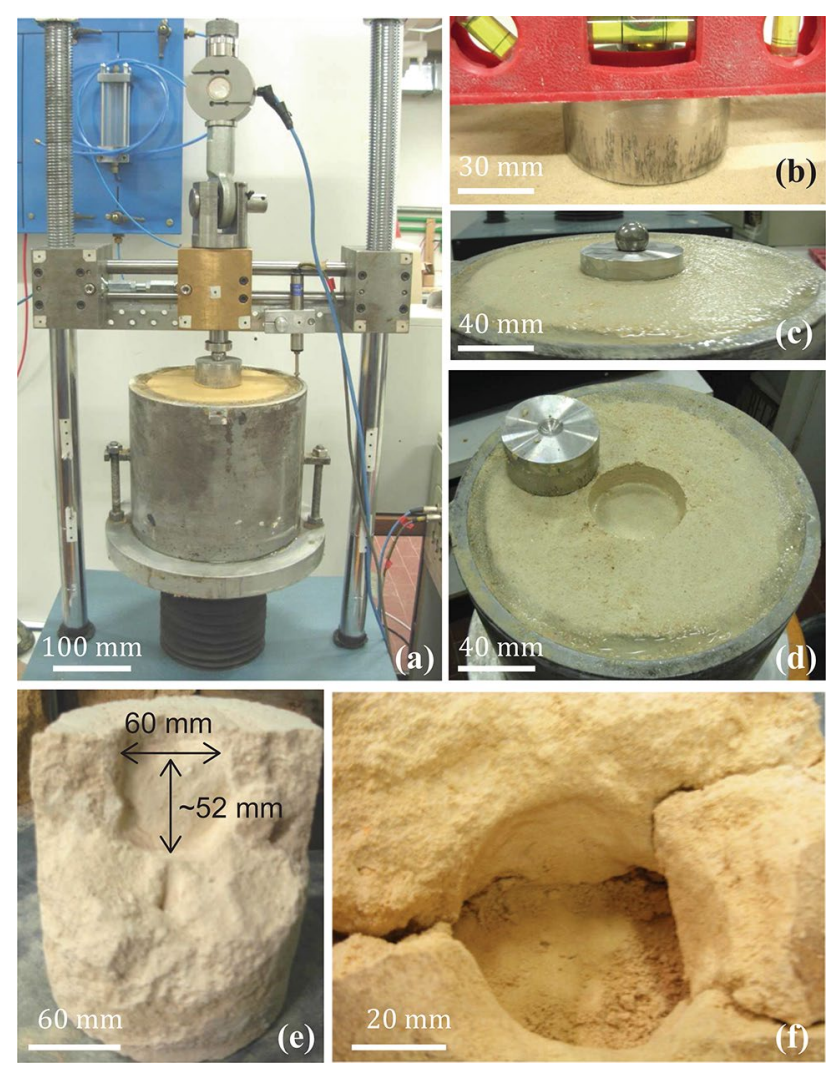

Fig. 10 a Experimental apparatus; b-d typical punching behaviour; e, f pictures of typical debonded bulbs just below the foundation

punching mechanism transforming the calcarenite into an unbonded soil just located in a bulb below the foundation (see Fig. 10d-f). The experimental load-displacement curve is characterized by an initial linear path until a specific point described as the generalized yielding point (see Fig. 11a) followed by a nonlinear hardening characterized by an increase in bearing capacity as the vertical displacement, $s_{\mathrm{v}}$, increases (Nova and Parma 2011). Concerning the numerical simulation, it can be observed that the dry and wet behaviour of the calcarenite is very well captured by the model in terms of load displacement curves for the different environmental conditions (i.e. dry and wet) which are considered by assuming a value of $S_{\mathrm{r}}=0$ and 1 for the dry and wet foundation, respectively. The $F E$ results also show that, as the prescribed vertical settlement of the rigid footing increases, the stresses below the foundation increase and that the yielding of the rock mainly develops in tabular zone that propagates in depth forming a plastic bulb. This can be observed in Fig. 11b, c, in terms of evolution of the bonding internal variable $p_{m}$ and volumetric plastic strains, respectively. Interestingly, there is a very good match in terms of size and shape of the plastic bulb determined numerically (Fig. 11b, c) and experimentally at the end of the test (Fig. 10e, f).

\subsection{BVP\#2: STD and LTD Processes Inducing Model Pillar Failure}

The second BVP simulation is devoted to reproduce the failure of a pillar induced by a $L T D$ process occurring after a $S T D$ process (see Fig. 12a). The experimental test simulates the degradation processes that might occur in a rock pillar within an underground cavity, when the rock is first soaked by water and then subjected to chemical weathering (Castellanza et al. 2008). As the applied vertical stress is smaller than the saturated strength of the calcarenite, the $S T D$ will not induce failure, whereas similar experiments where the pillar failure is induced by $S T D$ are reported in Ciantia et al. (2015b).

The testing layout and an illustration of the different stages of the test are shown in Fig. 12a, b, respectively. Figure $12 \mathrm{c}$ shows the problem geometry, the spatial discretization adopted in the $F E$ simulation and the assumed boundary conditions. In the first stage of the test (OA), the specimen is loaded in uniaxial conditions, starting from a dry state. Then the specimen is saturated at constant axial stress by imposing 


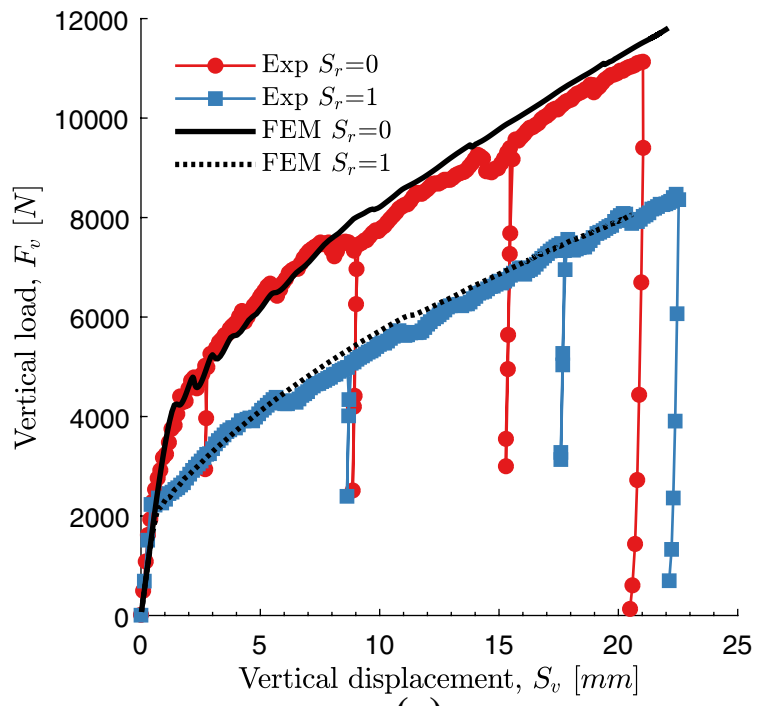

(a)

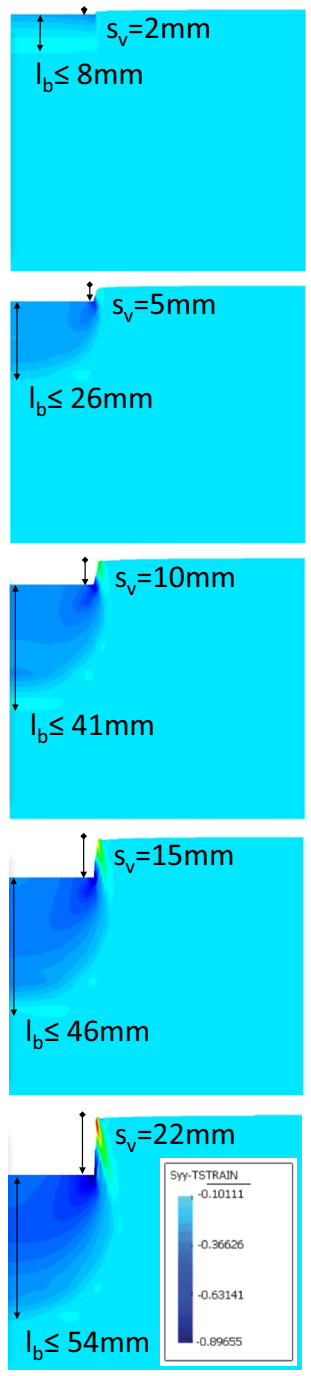

(b)
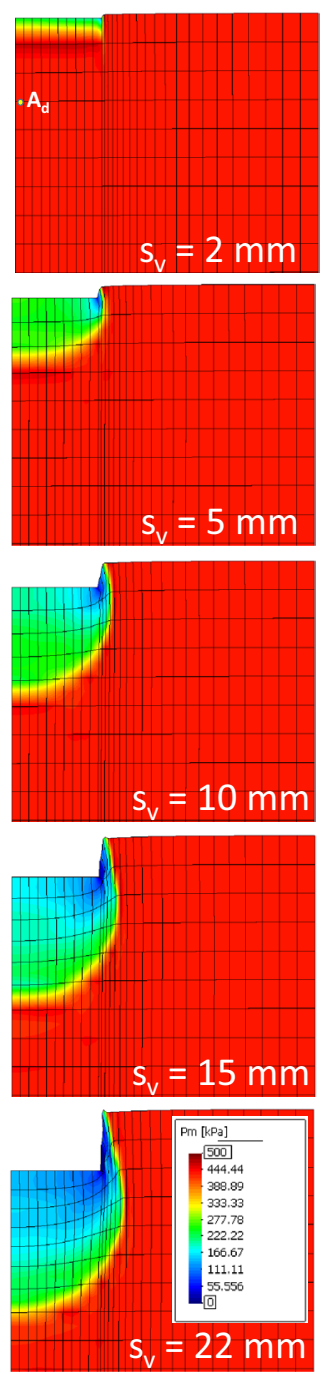

(c)
Fig. 11 a Experimental results and numerical simulation in $\left(S_{\mathrm{r}}=0\right)$ and wet $\left(S_{\mathrm{r}}=1\right)$ conditions; $\mathbf{b}$ evolution of vertical plastic strains and $\mathbf{c}$ bonding variable $p_{m}$ under the model footing an upward water flow (stage $\mathrm{AB}$ ), up to full saturation (stage $\mathrm{BC}$ ) during a period of $2 \mathrm{~min}$. It can be observed how the sample deforms due to the stiffness reduction experienced during the $S T D$ (Fig. 13a). In the final stage of the test (CD), the specimen is brought to failure by a long-term exposure to an acid solution $(\mathrm{pH}=3.7)$ on the lateral surface. The isochrones of the computed $S_{\mathrm{r}}, \xi_{\text {dis }}$ and $p_{\mathrm{m}}$ are shown in Fig. 14. The first three columns ( 0 to $10 \mathrm{~min}$ ) show the effect of the $S T D$, driven by an increase in $S_{\mathrm{r}}$ from the bottom of the specimen, on the boding-related internal variable $p_{\mathrm{m}}$. The last three columns (20 to $70 \mathrm{~min}$ ) show the effect of the $L T D$, driven by an increase in $\xi_{\text {dis }}$ from the lateral boundary of the specimen, on $p_{\mathrm{m}}$. The response of the material during the first loading stage-performed in steps-is almost linearly elastic. The subsequent STD produces additional deformations during the wetting stage. The progressive chemical dissolution of intergranular bonds gives rise to progressively increasing deformations with time at constant stress, eventually leading to the failure of the specimen when the reduction in uniaxial rock strength due to the LTD is such that the axial load cannot be sustained any longer. The FE simulations, as demonstrated by the comparison between experimental observations and numerical predictions, are used to calibrate the diffusion tensor $D_{i j}$ to correctly capture this behaviour. In the simulation, the dissolution constants $K_{1}$ and $K_{2}$ are taken from the work of Ciantia (2013) that obtained them performing dissolution tests on the same calcarenite. The computed isochrones of the axial stress $\left(\sigma_{y}\right)$ and of $\xi_{\text {dis }}$ along a radius at the specimen mid-height are shown in Fig. 13b, c, respectively. As the acid flows into the specimen from the lateral boundary, the values of $\xi_{\text {dis }}$ are not uniform along the section, but minimum at the specimen axis and maximum at the boundary. The inhomogeneous degradation process resulting from the horizontal acid flow causes a progressive weakening of the external portion of the specimen that induces a reduction in axial stress close to the lateral boundary and a corresponding stress increase at the specimen axis, due to stress redistribution within the specimen. This phenomenon is qualitatively similar to the one observed in the pillars of abandoned mines (Fig. 12d) or in ancient temple columns (Fig. 12e) when the intact rock is exposed to long-term chemical degradation (Parise and Lollino 2011; Tamagnini et al. 2002).

\section{Damage Analysis of Buildings Built on Top of an Abandoned Cavity in Canosa di Puglia}

The $B D I(t)$ of the complex 3D geometry concerning the interaction of a cave (excavated about two centuries ago) and two buildings in a PG3 zone (Fig. 1) is here addressed. It should be noted that such situations are extremely common 


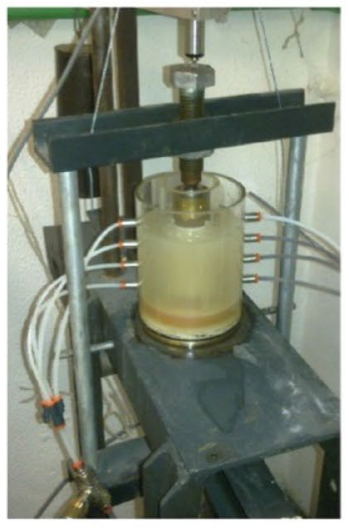

(a)

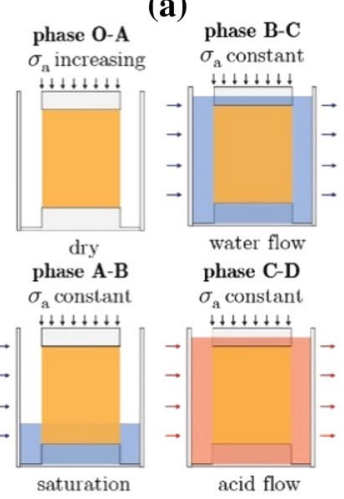

(b)

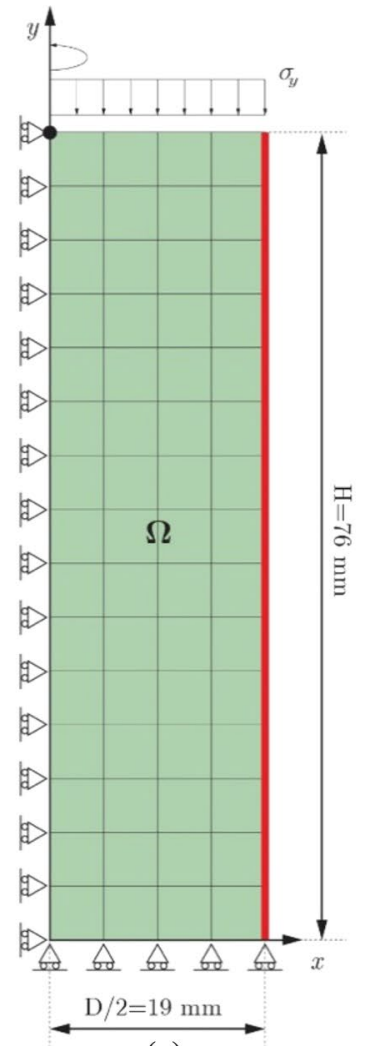

(c)

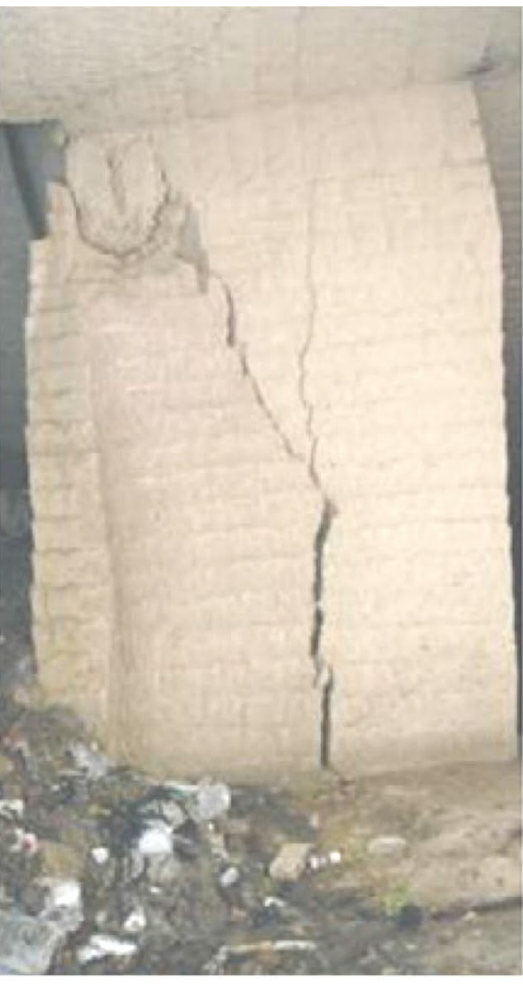

(d)

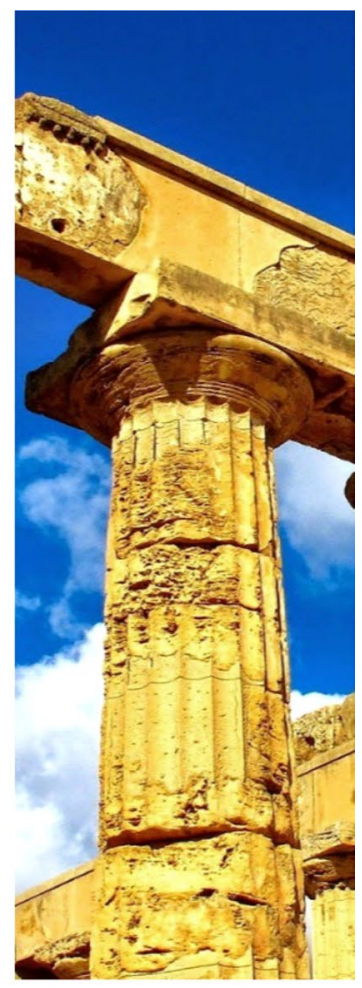

(e)
Fig. 12 a Small-scale pillar weathering test-experimental setup (Ciantia et al. 2015b); b description of testing stages; c geometry, spatial discretization and boundary conditions $\mathbf{d}$ example of failed calcarenite pillar (Parise and Lollino 2011) and e weathering affecting an ancient column of a temple in Selinunte (Sicily, IT)

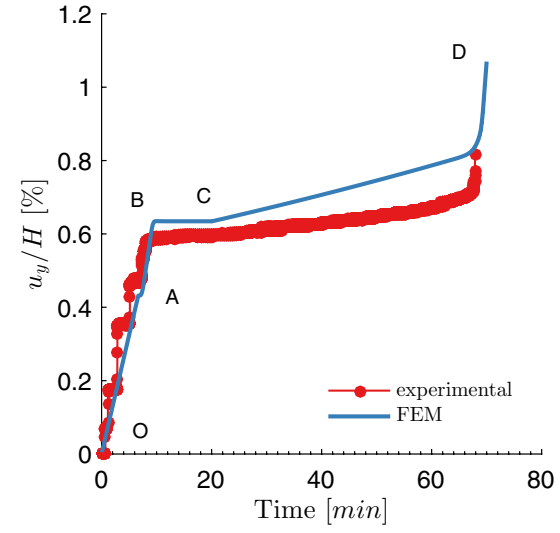

(a)

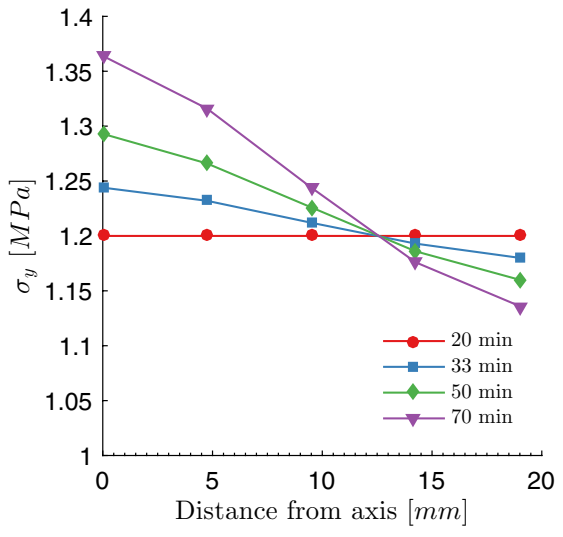

(b)

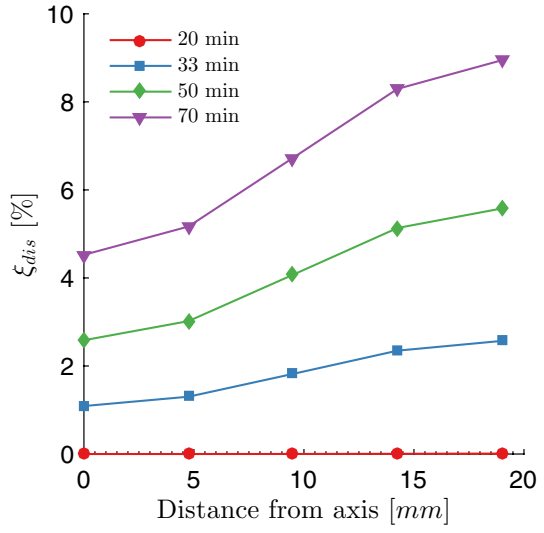

(c)

Fig. 13 FE simulation of the small-scale pillar weathering test: a displacement time experimental and numerical results; $\mathbf{b}$ isochrones of axial stress with distance from pillar axis; $\mathbf{c}$ isochrones of $\xi_{\text {dis }}$ with distance from pillar axis

in the Apulian region (Parise and Vennari 2017), but this particular case study is considered as the authors were directly involved with the risk assessment of this cavity
(Ciantia et al. 2015c) and hence disposed of in situ material needed for the model calibration (see Sect. 4). The current global stability of the same geosystem determined by means 


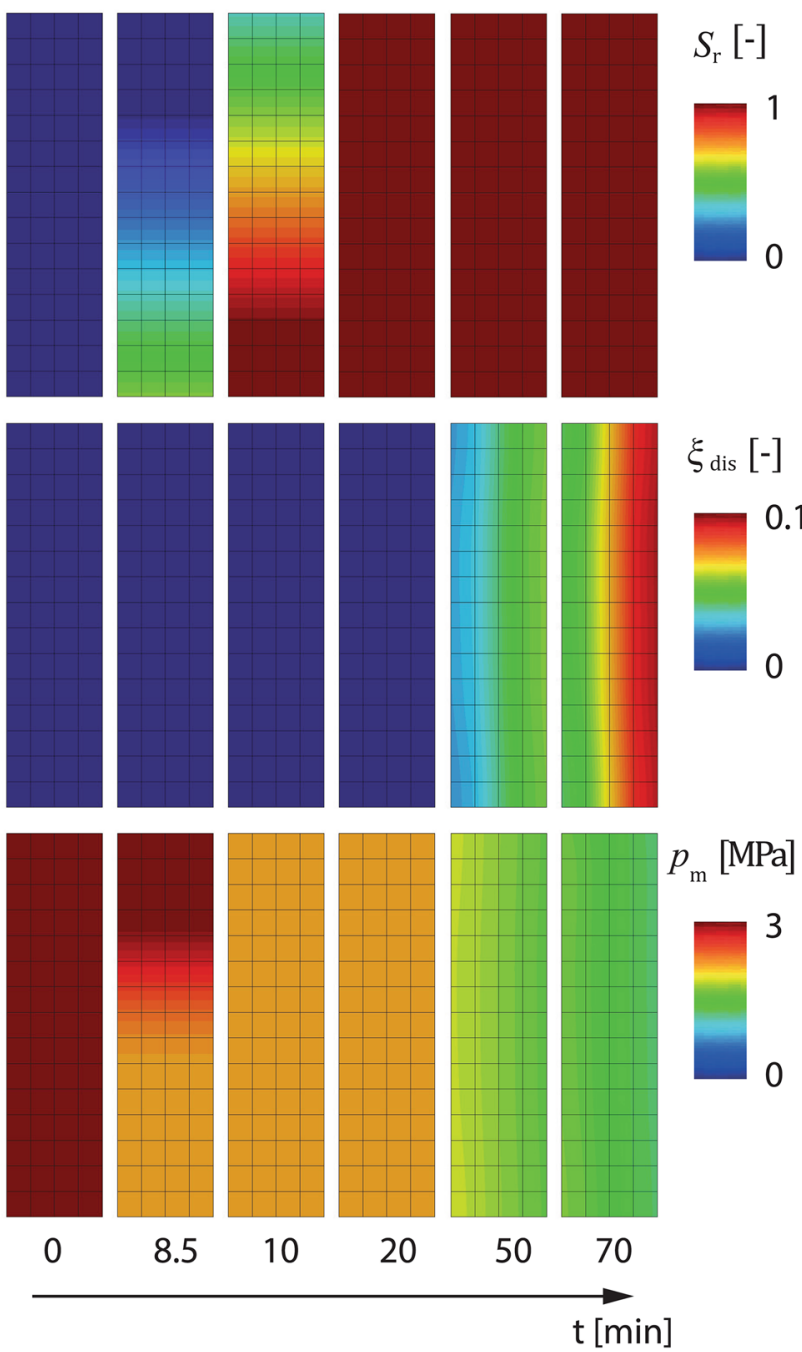

Fig. $14 F E$ simulation of the small-scale pillar weathering test: isochrones of $S_{\mathrm{r}}$ (first row), $\xi_{\mathrm{d}}$ (second row)and $p_{\mathrm{m}}$ (third row) with time. Each snapshot represents half a sample as represented in Fig. 12c

of the standard $c-\phi$ reduction method (Potts et al. 1990) resulted to be 3.4 and 1.5 for the dry and saturated states, respectively (Ciantia et al. 2015c). Despite this current stable condition in both dry and saturated conditions, it is known that the long-term weathering of the rock could lead to subsidence and eventually to a failure mechanism such as the one in Fig. 2 (Ghabezloo and Pouya 2006). The BDI(t) as introduced in Sect. 2 is hence used to tentatively predict the evolution of the damage on the buildings under study. The weathering scenario assumed consists of two phases:

1. a saturation phase (STD process) that could be induced by heavy rainfalls or leakages from water supplies.

2. a long-term dissolution phase (LTD process) assuming the cavity remains saturated for long periods of time in an open-system scenario (dissolved calcite ions are washed away).

The laboratory tests on the calcarenite collected in situ were used to calibrate the initial mechanical properties of the material which, assuming them to be the same for all the domains, were assigned as the model's initial state. During phase 1 , simulated by setting $S_{\mathrm{r}}=1$ and hence using the 'wet' mechanical properties for the calcarenite, the geosystem remains in equilibrium. For this reason, in what follows, only the long-term chemical damage is considered (phase 2). In the absence of environmental hydraulic field data and boundary conditions, inspired by Ghabezloo and Pouya (2006), the cave boundaries were exposed to a different acidic $\mathrm{pH}$ environment. Such boundary conditions trigger the development of a coupled chemo-mechanical diffusion and deformation process. To consider the real geometry of the problem and realistic building loads, a 3D numerical analysis is performed, and the mesh and problem definition are shown in Fig. 15a, b. To highlight the importance of the three-dimensionality of the problem, a 2D plain strain analysis in correspondence of section $\mathrm{A}^{-\mathrm{A}^{\prime}}$ is also performed. The mesh of section $\mathrm{A}-\mathrm{A}^{\prime}$ and the problem definition are shown in Fig. 15c. For the 3D FEM model discretization, 46,961 quadratic tetrahedral H10P4C4 elements (67,581 nodes and 169,270 degrees of freedom) are used, while the $2 \mathrm{D}$ model is meshed with 1879 triangular T6P3C3 elements (3920 nodes and 8642 degrees of freedom). Standard displacement boundary conditions have been applied to the external boundaries, with fixed horizontal and vertical displacements at the bottom and fixed horizontal displacements on the lateral boundaries. The external loads (i.e. the foundation loads) acting at the ground surface are kept constant, while the $L T D$ process evolves from the inner boundary of the cave. To represent building A (see Fig. 1), a pressure of $150 \mathrm{kPa}$ is imposed under each of the 9 square footings, while a pressure to represent building $\mathrm{B}$ a uniform pressure of $40 \mathrm{kPa}$ is imposed under the area covered by it. For the $2 \mathrm{D}$ analysis, the same pressure of building $\mathrm{A}$ is applied despite the 2D geometrical limitations (plain strain hypothesis). On the cavity surfaces, a fixed constant concentration of $\left[\mathrm{H}_{3} \mathrm{O}^{+}\right]$ions, corresponding to a $\mathrm{pH}$ of 6.7 , is imposed. They will propagate into the rock by means of a diffusive phenomenon causing the long-term dissolution of $\mathrm{CaCO}_{3}$. The reactive transport model parameters used for the simulations are those of $B V P \# 2$ and are summarized in Table 5. To highlight the importance of the cavity environmental conditions, two further 3D simulations were run: one imposing a $\mathrm{pH}$ of 7.5 , while in the other, the $\mathrm{pH}$ imposed at the cavity boundaries was set to 6 .

Figures 16 and 17 report the main results as a function of physical time (days) from the beginning of the weathering process assumed (i.e. the $L T D$ process) for the $2 \mathrm{D}$ and $3 \mathrm{D}$ 
Fig. 15 a, b 3D mesh and sections considered for the BDI calculation, and $\mathbf{c}$ section, mesh, boundary and initial conditions and environmental loads for $2 \mathrm{D}$ simulation

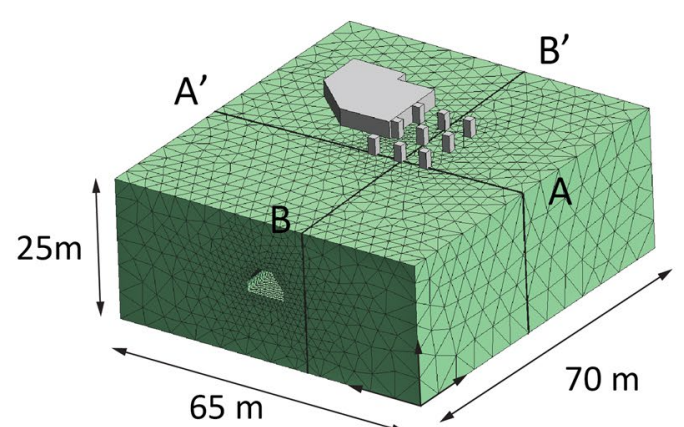

(a)

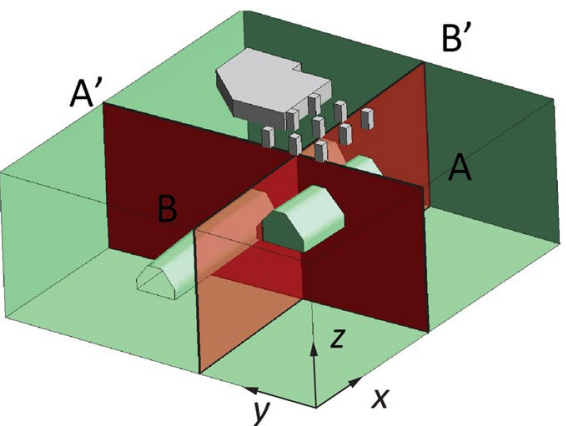

(b)

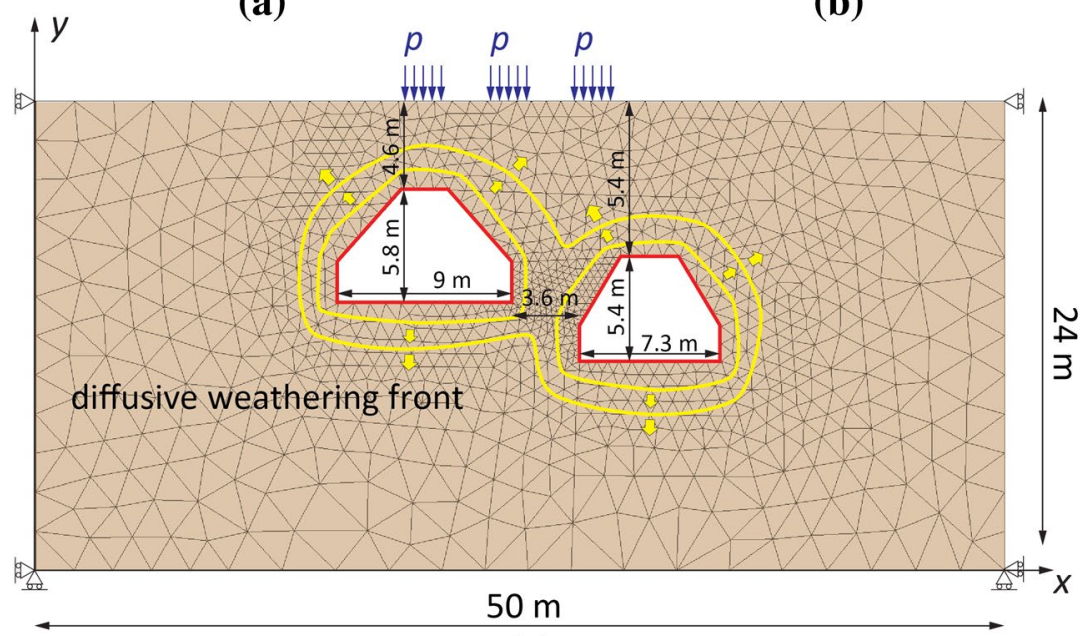

(c)

simulations, respectively, for the $6.7 \mathrm{pH}$ simulations. The dissolution process that evolves from the inner boundary is shown in the first column of Fig. 16 by the contour in time and space of the contaminant ion $\left[\mathrm{H}_{3} \mathrm{O}^{+}\right]$. As the contaminant concentration increases, the dissolution process evolves causing a mass reduction and a consequent increase in the scalar $\xi_{\text {dis }}$ leading to a reduction in the bonding-related variables $p_{m}$ and $p_{t}$ (2nd column of Figs. 16 and 17). This strength reduction causes yielding of the rock to concentrate in correspondence of the partition wall for both the 2D and $3 \mathrm{D}$ simulations. As the exposure time with the $\left[\mathrm{H}_{3} \mathrm{O}^{+}\right]$ions increases, the plastic strains localize into a shear band (3rd column) and the displacements increase (4th column). Nevertheless, before plastic strains localize into a shear band, as clearly shown in Fig. 18a, material degradation developing from the wall boundaries induces a stress redistribution in the partition wall Fig. 18b. Although non-local approaches (Conte et al. 2010) should be adopted to avoid mesh dependency when looking at the failure mechanism, it was observed that further mesh refinement did not change the results of the simulation in terms of surface displacement with time. Interestingly, the failure of the partition wall does not cause a global failure mechanism, and this is due to the residual frictional strength within the shear band combined with the rooftop geometry. In fact, as represented in Fig. 18c, d, the stress corresponding to a point within the shear band starts from an initial elastic state, yields after about 120 days of acid exposure and evolves until critical state is reached. Figure 19 shows comparison of the displacement field for the $2 \mathrm{D}$ and $3 \mathrm{D}$ numerical simulations used to calculate the $B D I$ for the $6.7 \mathrm{pH}$ environment. The chemo-mechanical coupled induced displacements are well documented in terms

Table 5 Reactive transport parameters and initial conditions

\begin{tabular}{llllllll}
\hline Porosity, $n(-)$ & $\begin{array}{l}\text { Darcy isotropic per- } \\
\text { meability }\left(\mathrm{m}^{2}\right)\end{array}$ & $\begin{array}{l}\text { Isotropic diffusion coef- } \\
\text { ficient, } D\left(\mathrm{~m}^{2} / \mathrm{s}\right)\end{array}$ & $K_{1}(1 / \mathrm{s})$ & $K_{2}(1 / \mathrm{s})$ & $\begin{array}{l}{[\mathrm{CaCO}]_{0}} \\
\left(\mathrm{~mol}^{3} / \mathrm{m}^{3}\right)\end{array}$ & {$\left[\mathrm{H}^{+}\right]_{0}\left(\mathrm{~mol} / \mathrm{m}^{3}\right)$} & $\mathrm{pH}$ \\
\hline 0.59 & $1 \mathrm{e}-12$ & $1.16 \mathrm{e}-7$ & $-1 \mathrm{e}-10$ & -1.6 & 25,190 & 0.001 \\
0.59 & $1 \mathrm{e}-12$ & $1.16 \mathrm{e}-7$ & $-1 \mathrm{e}-10$ & -1.6 & 25,190 & $1.65 \mathrm{e}-4$ \\
0.59 & $1 \mathrm{e}-12$ & $1.16 \mathrm{e}-7$ & $-1 \mathrm{e}-10$ & -1.6 & 25,190 & $3.16-5$ & 6.00 \\
\hline
\end{tabular}




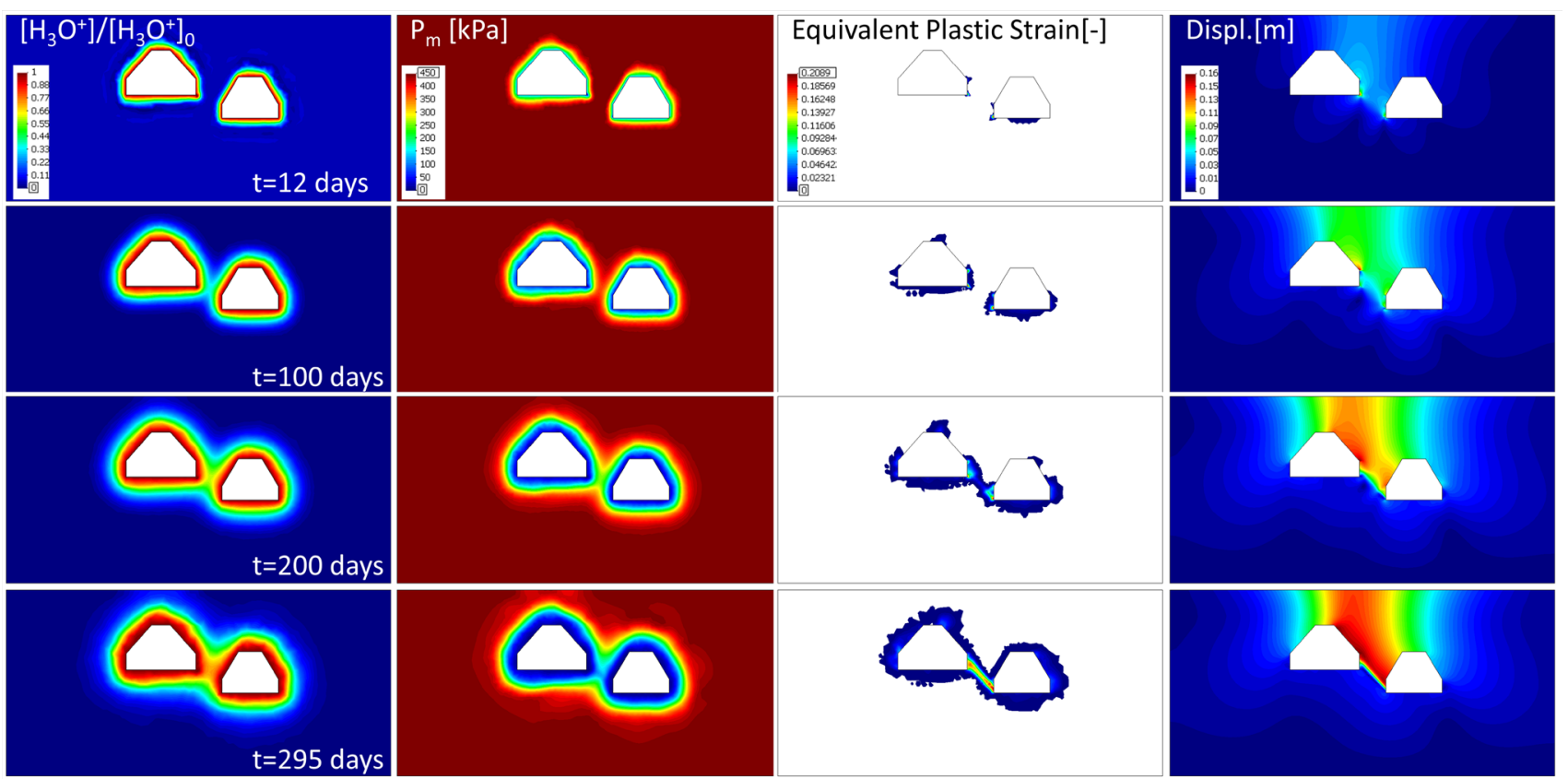

Fig. 16 2D FEM results: contour results by increasing time for the $L T D$ process (considering column): \#1 evolution of $\left[\mathrm{H}_{3} \mathrm{O}^{+}\right]$contaminant; \#2) internal variable related to bond strength $p_{\mathrm{m}}$; \#3) equivalent plastic strains; \#4) displacement modulus
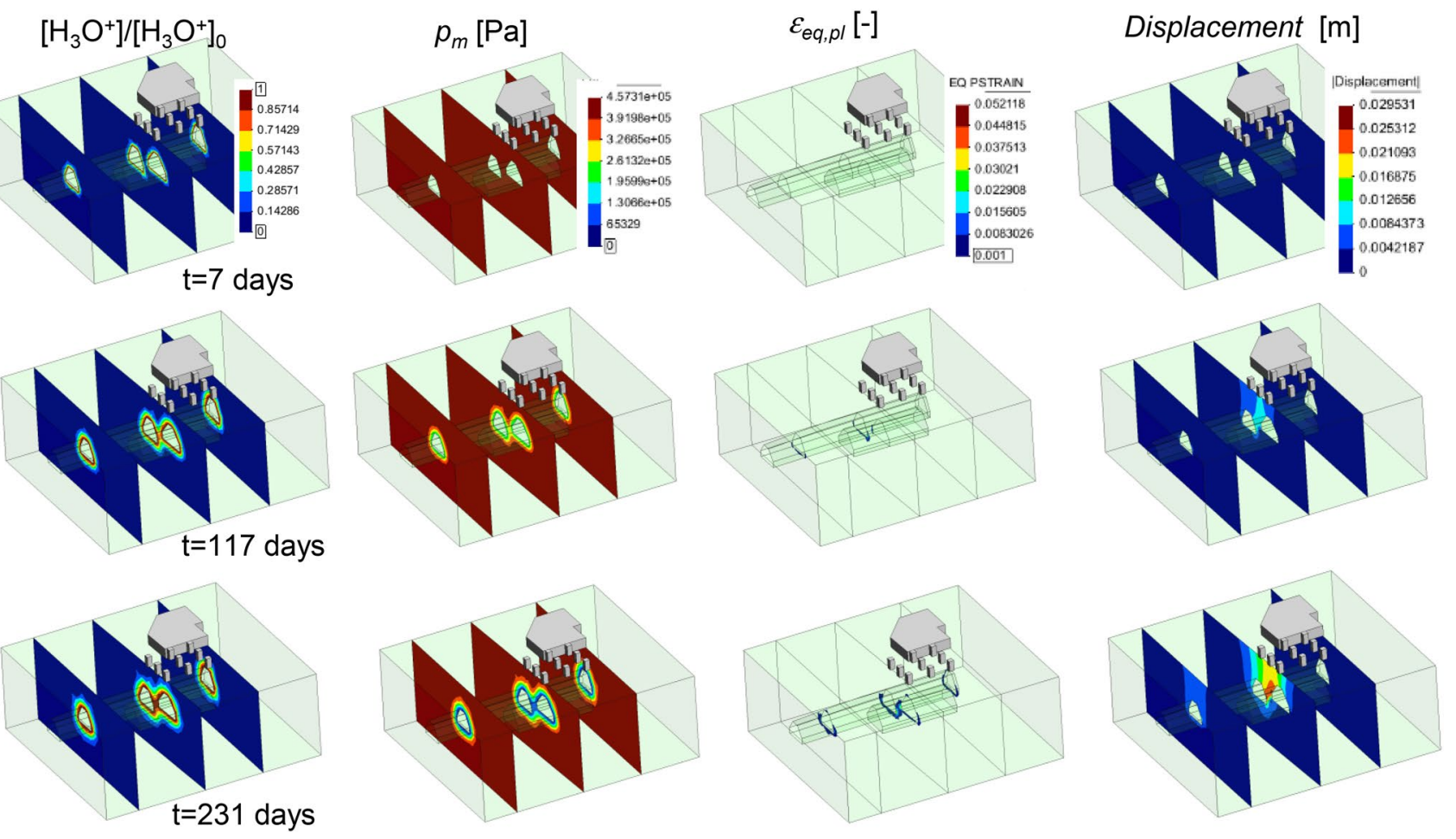

Fig. 17 3D FEM results: contour results by increasing time for the LTD process (considering column): \#1 evolution of [ $\left.\mathrm{H}_{3} \mathrm{O}^{+}\right]$contaminant; \#2) internal variable related to bond strength $p_{\mathrm{m}}$; \#3) equivalent plastic strains; \#4) displacement modulus 


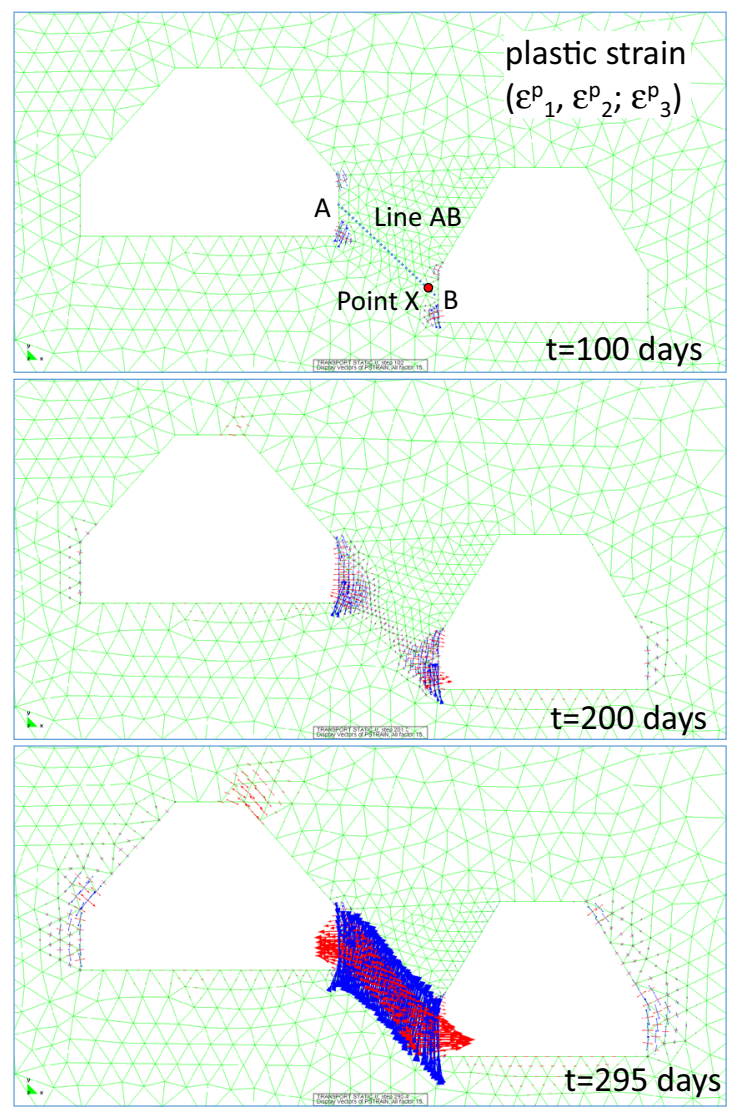

(a)

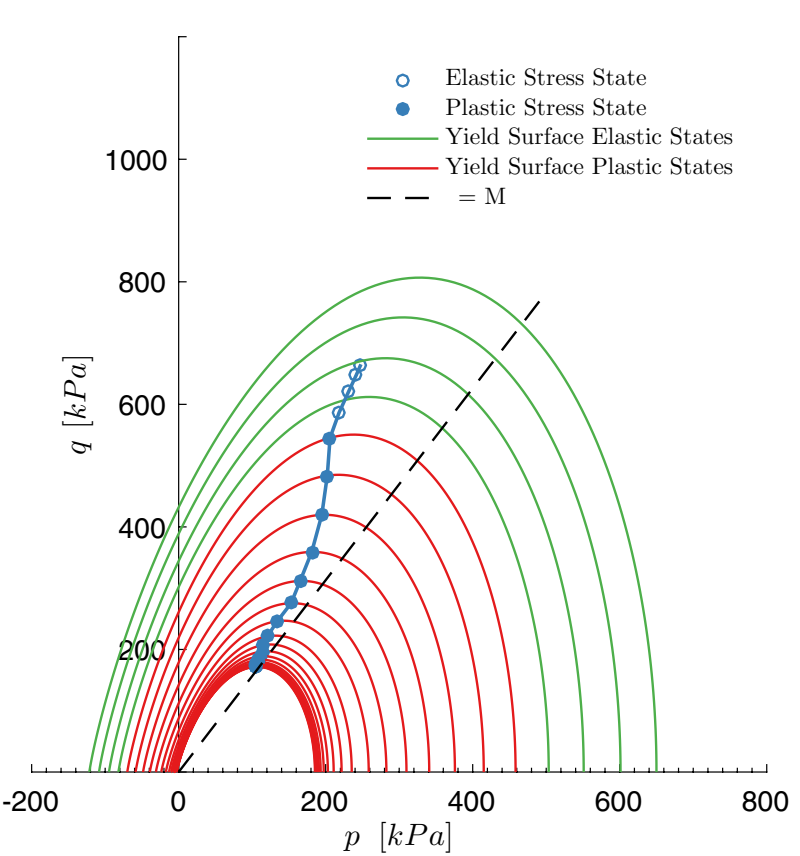

(c)

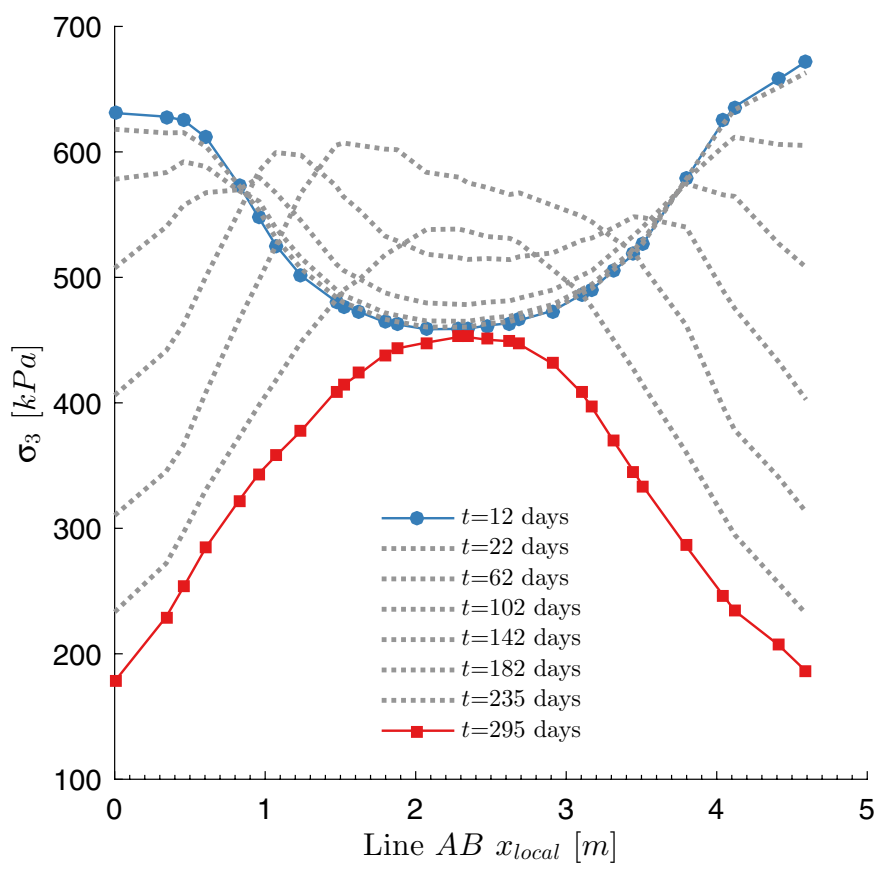

(b)

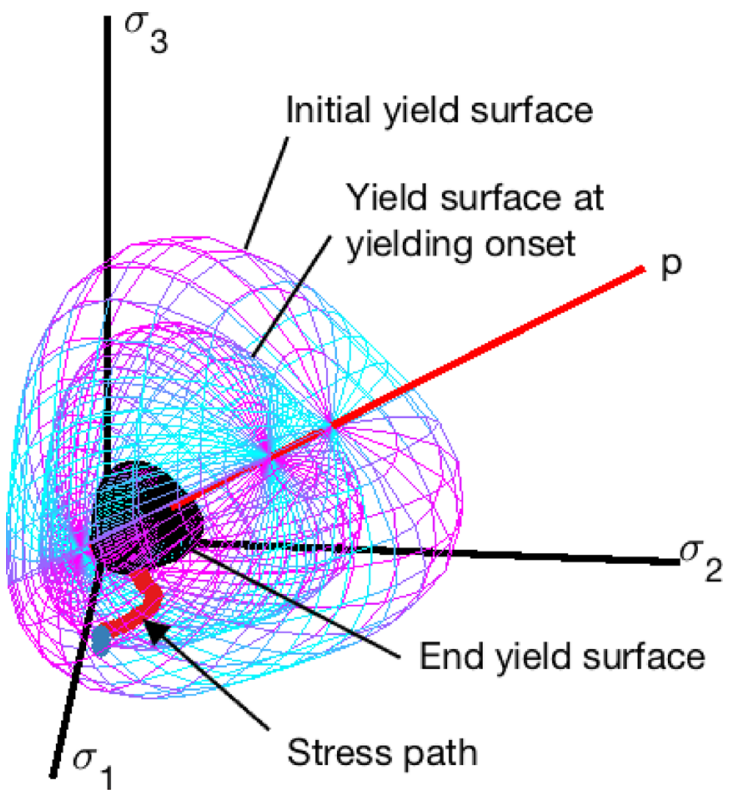

(d)

Fig. 18 LTD process: a evolution of principal plastic strain, $\mathbf{b}$ evolution of principal stress $\sigma_{3}$ along line A and B and stress path for point X along line $\mathrm{AB}$ on $\mathbf{c}$ rotating triaxial plane and $\mathbf{d}$ principal stress space 

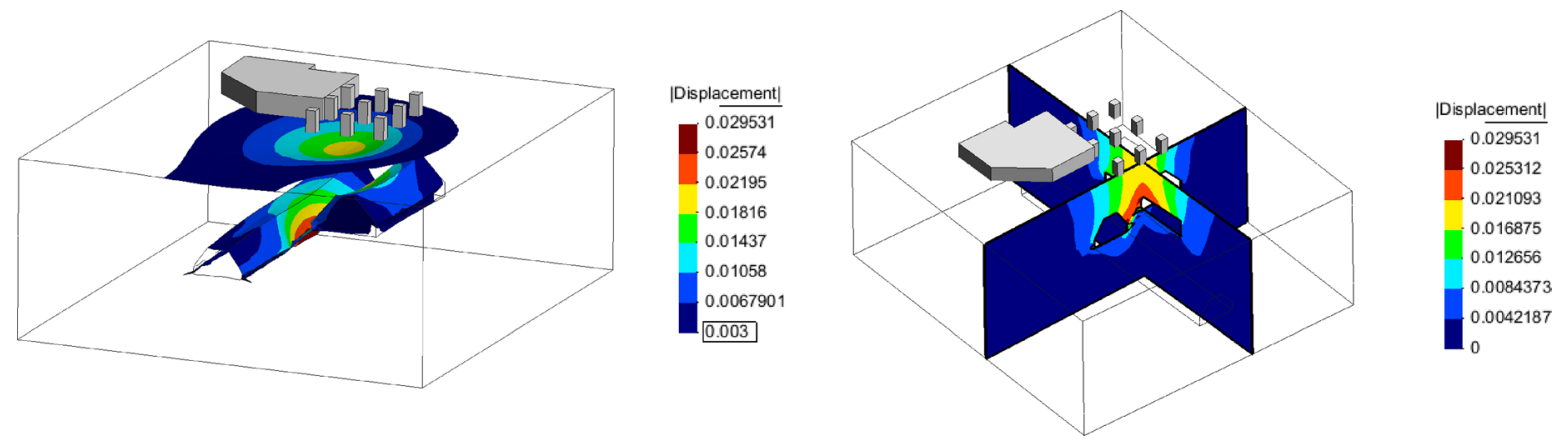

(a)

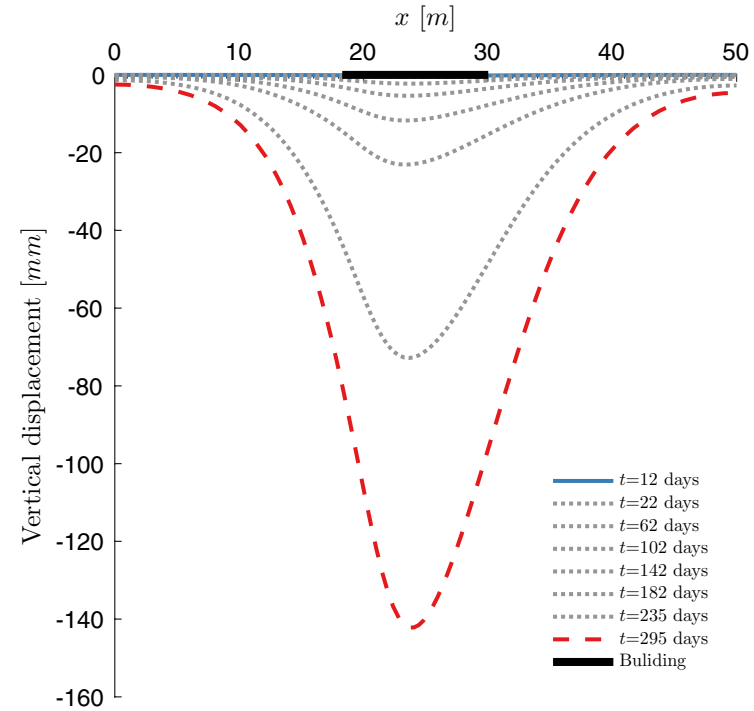

(b)

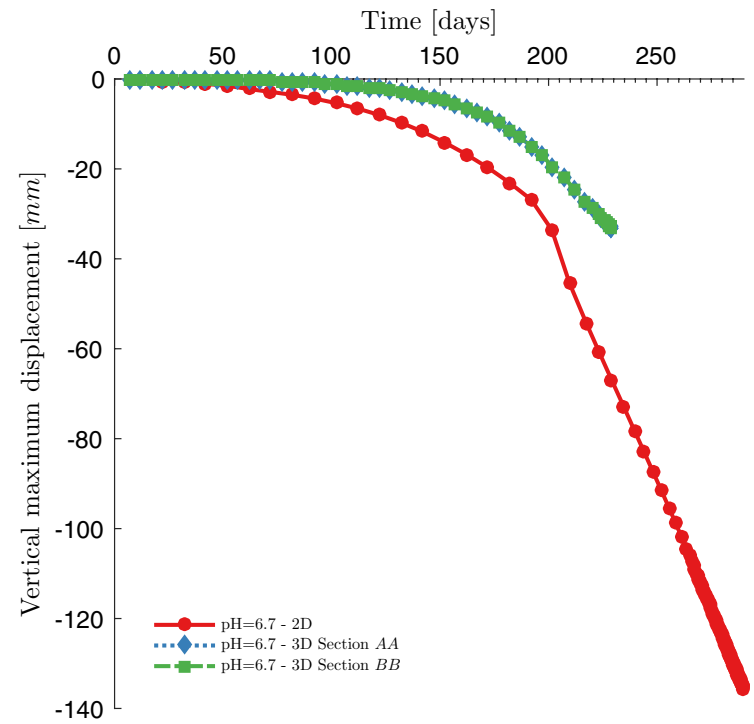

(d)

Fig. 19 Simulation results for $\mathrm{pH}=6.7$ : a displacement contours of 3D FEM results showing subsidence basin induced by partition wall failure; 2D b and 3D c vertical displacements curves used to calculate

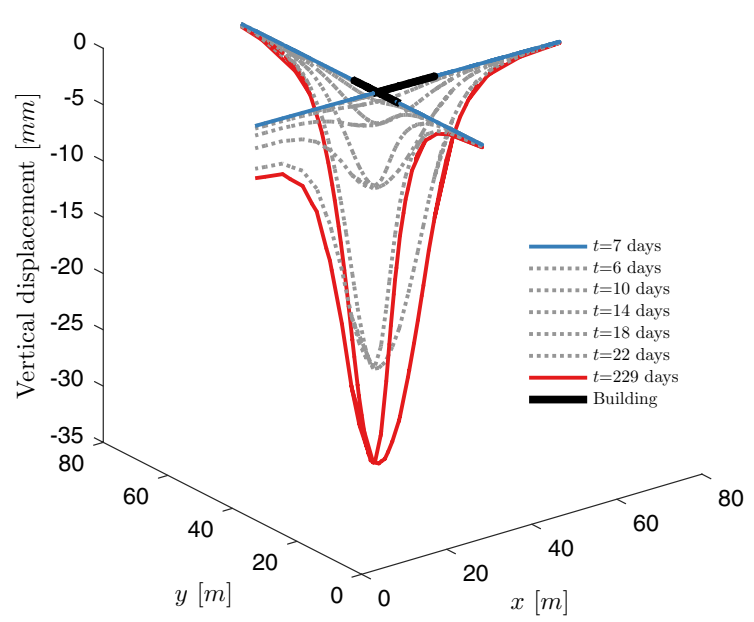

(c)

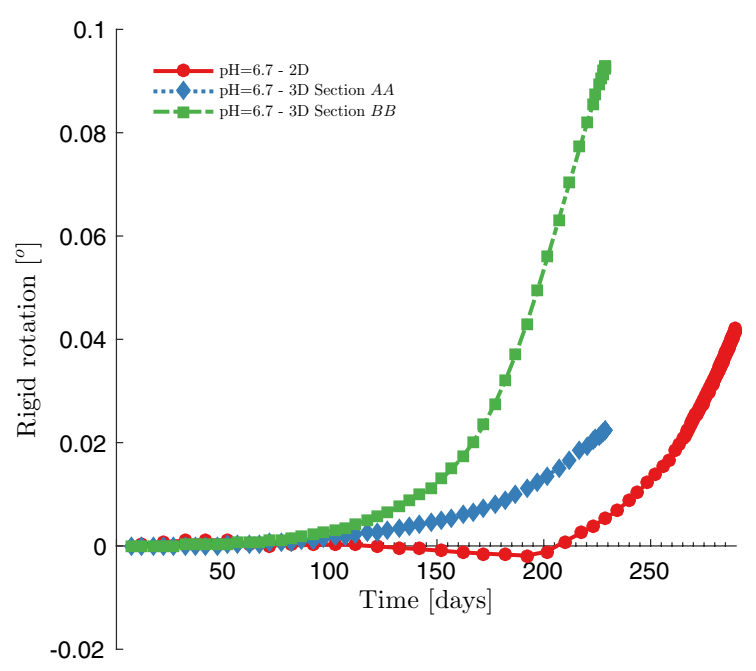

(e)

the $B D I$; d maximum vertical surface displacement temporal evolution time for 2 and 3D analysis, e rigid rotation vectors induced by $L T D$ process 


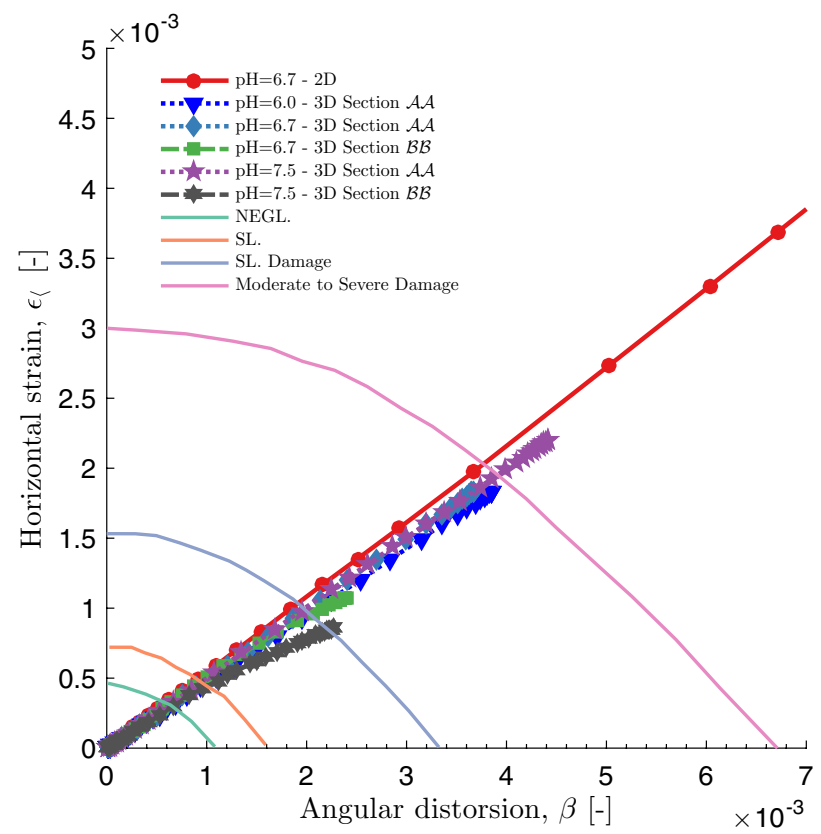

(a)

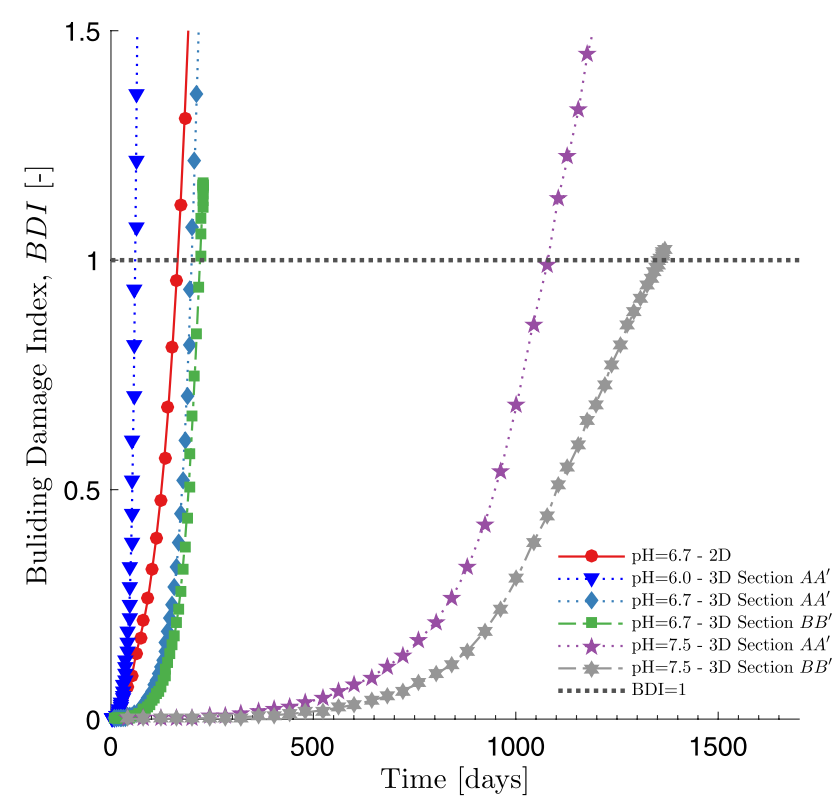

(b)

Fig. 20 a Building angular distortion-horizontal strain paths for the 2D and 3D FEM simulations in the Boscardin and Cording (1989) abacus and $\mathbf{b}$ corresponding temporal evolution of the building damage index $B D I(t)$

of the displacement contours (Fig. 19a) for the 3D simulation. The vertical displacement profiles with time for the 2D and 3D (section A-B) simulations are in Fig. 19b, c. The displacement time curves for the point with maximum surface displacement and the buildings rigid rotation evolution with time for the simulations run are reported in Fig. 19d, e. As expected, the 2D simulation deforms more than the $3 \mathrm{D}$ one thanks to the lateral support provided by the rock not intersected by the tunnel. The change in curvature of the displacement time curve (more visible for the 2D case) can be identified as the sinkhole inception time as from this point onward the displacement will accelerate until the simulations stops converging. Interestingly, the surface subsidence observed in the 3D simulation acquires a circular shape, and it is caused by the failure of the partition wall. Finally, in Fig. 20a the angular distortion horizontal strain paths for the 2 and 3D analyses with different $\mathrm{pH}$ conditions are reported. By means of Eq. (1), in Fig. 20b, the BDI evolving with time is also reported. The time needed to attain a $B D I$ of one results to be 1080, 200 and 60 days for the 7.5, 6.7 and $6 \mathrm{pH}$ case, respectively. The plot also shows how the three-dimensional effect delays the $B D I$ attaining a value of unity from 165 to 200 days for the $6.7 \mathrm{pH}$ simulation. In this contribution, only two sections were considered for the $B D I$ assessment of building $\mathrm{A}$; however, any section can be analysed and the final $B D I(t)$ would be the first one (section $\mathrm{A}-\mathrm{A}^{\prime}$ in this simulation) reaching a value of 1 .

\section{Conclusions}

Many abandoned man-made caves induce sinkholes because of the degradation of the constituent soft rock. In this paper, the problem superficial subsidence prior to sinkhole formation in urban area is tackled and in particular:

(i) A procedure to determine the temporal evolution of settlement damage to buildings by means of a building damage indicator, namely the building damage index, $B D I$ is proposed. The weathering-induced temporal evolution of horizontal strain and angular distortion are used to introduce physical time to the $B D I$ which is a practical scalar index of the evolution of serviceability of buildings.

(ii) Despite all the limitations intrinsic to standard $F E$ and local constitutive relationships, for the first time, a 3D numerical approach including the reactive transport of chemical species and an advanced strain-hardening plasticity constitutive model was used to tentatively predict the $B D I(t)$.

(iii) To introduce a time-dependent building damage index, a weathering scenario must be assumed and consequently modelled. For this reason, the reactive transport of chemical species is fundamental as it enables to describe the spatial-temporal evolution of chemical species that reproduce numerically the assumed weathering scenario. The reliability of the 
approach increases as the weathering mechanism reproduced is more realistic and with the soundness of the constitutive model which has to be hydrochemo-mechanically coupled. It is shown how $B D I$ is strongly dependent on the weathering scenario assumed.

(iv) In order to determine the $B D I(t)$ of a real building on an abandoned cavity in Southern Italy, standard mechanical and advanced chemo-hydro-mechanical $(C H M)$ experimental tests on the in situ rock are performed and used to calibrate the constitutive model which accounts for the hydro-chemical damage effects induced by weathering.

(v) Two model footing tests on a dry and wet calcarenite were performed, and a further small-scale boundary value experimental test from the literature is simulated to test the soundness of the model and the $F E$ code to deal with $C H M$-coupled boundary value problems.

(vi) For all simulations of the $L T D$-induced damage of the abandoned anthropic cavity, the $B D I$ attained a value of 1 well before the progressive failure mechanisms starts to develop. For the same weathering scenario (6.7 $\mathrm{pH}$ case), smaller displacements are observed in the 3D model with respect to the $2 \mathrm{D}$ analysis and the $B D I$ attains a value of one after a longer time.

(vii) A plane strain $2 \mathrm{D}$ analysis followed by three more realistic 3D FEM stability analyses is performed. In all cases, the numerical results show that weathering of the porous rock causes displacements at the ground level that, before accelerating, slowly increases with time. Plastic strains begin to develop at the corners of the cavity by the partition wall well before they start to localize into a shear band. This plastic strain evolution induces a lot of stress redistribution within the rock. Despite the mesh dependency limitations, this result may suggest that such local failures can be very useful as collapse premonitory signs as in the model they start developing few months before failure. This is in accordance with what observed in the 2007 Gallipoli sinkhole where evident signs of damage on pillars were observed months before the collapse (Delle Rose 2007).

(viii) Despite the non-symmetric geometry of the two cavities, the subsidence basin in the $3 \mathrm{D}$ analysis assumes a circular shape, which is typical for the sinkholes observed in these rocks (Parise and Lollino 2011). As recently observed by Nof et al. (2013) and Jones and Blom (2014) with interferometric synthetic aperture radar (inSAR), subsidence basins can be used a precursory signs of sinkhole formation. Interestingly, also the 3D FEM simulation presented here captures this feature. (ix) The numerical predictions show that, for open-system scenarios, it results that serviceability conditions are lost after 65 days of exposure in acidic environment (pH6), whereas the same level of damage is achieved after 3 years if the $\mathrm{pH}$ is set to 7.5. From an engineering perspective, the precautions to be taken to maintain the buildings in good serviceability conditions would be to monitor flood occurrence and to avoid the closing of ventilation raises. In fact, for this particular case, rock saturation an the corresponding STD would still not cause collapse and proper air ventilation would avoid the formation of aggressive acidic environments that, in the presence of water, would initiate the $L T D$.

Limitations of the $B D I$ include aspects inherent to most deterministic numerical models of geotechnical problems. In particular the reliability of the approach will depend on: (i) the amount (and associated uncertainty) of information required concerning the geometry of the problem, (ii) the CHM material properties, the chemical reactions and processes, (iii) local heterogeneities and (iv) the assumption of the weathering scenarios. Many of these inconveniences may be addressed by employing a probabilistic approach (Griffiths et al. 2002; Griffiths and Fenton 2004; Zhang and $\mathrm{Ng}$ 2005). We also believe that in a near future remote sensing techniques such as the interferometric synthetic aperture radar $(i n S A R)$ from satellite images will provide temporal evolution of subsidence that will allow to test and improve the reliability of the proposed methodology.

Acknowledgements The authors wish to thank Professors C. di Prisco, T. Hueckel, M. Pastor, C. Tamagnini for many fruitful discussions and Dr. Ariberto Sacco for helping in the experimental tests. M.O. Ciantia is particularly grateful to Prof. Roberto Nova for his passion and enthusiasm devoted to scientific investigation. The financial support by Spanish Research Program from Ministry of Economy and Competitiveness through the AQUARISK Project (ESP2013-47780-C2-2-R) and the Joint Programming Initiative on Cultural Heritage and Global Change (JPICH) through the PROTHEGO project is also acknowledged.

Open Access This article is distributed under the terms of the Creative Commons Attribution 4.0 International License (http://creativeco mmons.org/licenses/by/4.0/), which permits unrestricted use, distribution, and reproduction in any medium, provided you give appropriate credit to the original author(s) and the source, provide a link to the Creative Commons license, and indicate if changes were made.

\section{Appendix 1}

The convection-diffusion reactive equation that governs the contaminant transport problem (Eq. 4) is split in a pure advection system of partial differential equations (PDEs) solved using the Taylor-Galerkin discretization technique 
described in (Donea 1984; Löhner et al. 1984) already applied to both fluid dynamics and solid mechanics (Mabssout and Pastor 2003a, b; Peraire et al. 1986; Quecedo and Pastor 2002) and a system of ordinary differential equations solved with a fourth-order Runge-Kutta algorithm (Hirsch 1988; Lambert 1973). In particular, denoting with $\nabla$ the vector differential operator, Eq. (4) is written in a more compact manner as:

$\frac{\partial}{\partial t} \boldsymbol{\phi}+\bar{\nabla} \mathbf{F}=\bar{\nabla} \cdot(\mathbf{D} \bar{\nabla} \boldsymbol{\phi})+\mathbf{S}$

where we have introduced the vector of unknowns $\boldsymbol{\phi}=\left(\begin{array}{c}{\left[\mathrm{H}_{3} \mathrm{O}^{+}\right]} \\ {\left[\mathrm{CaCO}_{3}\right]}\end{array}\right)$, a flux vector $\mathbf{F}=\left(\begin{array}{c}\mathbf{q}\left[\mathrm{H}_{3} \mathrm{O}^{+}\right] \\ \mathbf{0}\end{array}\right)$, a $\overline{\boldsymbol{\nabla}}$ operator defined by $\bar{\nabla}=\left(\begin{array}{ll}\boldsymbol{\nabla} & 0 \\ 0 & \boldsymbol{\nabla}\end{array}\right)$, a diffusion matrix $\mathbf{D}=\left(\begin{array}{cc}D_{i j} & 0 \\ 0 & 0\end{array}\right)$ and a source vector $\mathbf{S}=\boldsymbol{\Gamma} \cdot \boldsymbol{\phi}$ with $\boldsymbol{\Gamma}=\left(\begin{array}{cc}0 & -K_{1} \\ -K_{2} & 0\end{array}\right)$. The system can also be written in a nonconservative form as:

$\frac{\partial}{\partial t} \boldsymbol{\phi}+\mathbf{Q} \bar{\nabla} \boldsymbol{\phi}=\mathbf{D} \bar{\nabla}^{2} \boldsymbol{\phi}+\mathbf{S}$

where we have supposed that $\boldsymbol{\nabla} \cdot \mathbf{q}=0$ as the flow is considered incompressible, $\mathbf{Q}=\left(\begin{array}{ll}\mathbf{q} & 0 \\ 0 & 0\end{array}\right)$ and where we have supposed constants diffusion coefficients.

The mass balance equation includes convection, diffusion and retardation effect due to the chemical reaction between calcite and acid ions. Equation (11) combines both parabolic and hyperbolic $P D E$ s with a source term $\mathbf{S}$, and it can be solved using a splitting operator technique in which each of the two operators, convective-diffusive transport and sources, is treated separately (Toro 2001):

$\left.\begin{array}{ccc}P D E & : & \frac{\partial}{\partial t} \boldsymbol{\phi}+\mathbf{Q} \bar{\nabla} \boldsymbol{\phi}=\mathbf{D} \bar{\nabla}^{2} \boldsymbol{\phi}+\mathbf{S}(\boldsymbol{\phi}) \\ \text { initial condition, IC }: & \boldsymbol{\phi}\left(\mathbf{x}, t^{n}\right)=\boldsymbol{\phi}^{n}(\mathbf{x})\end{array}\right\}$

We want to evolve $\boldsymbol{\phi}^{n}$ from time $t=t^{n}$ to the new value $\phi^{n+1}$ at $t=t^{n+1}$ by a time step $\Delta t=t^{n+1}-t^{n}$. Therefore, two problems will be considered:

(i) A diffusion-advection problem of the type

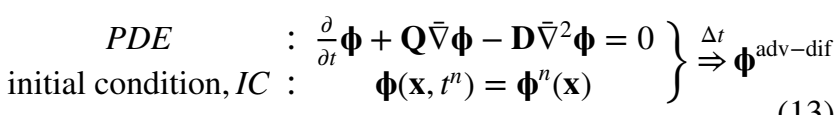

(ii) and the source problem, which is an ordinary differential equation $(O D E)$ :

$\left.\begin{array}{cc}O D E & : \quad \frac{\mathrm{d} \phi}{\mathrm{d} t}=\mathbf{S}(\boldsymbol{\phi}) \\ I C & : \boldsymbol{\phi}\left(\mathbf{x}, t^{n}\right)=\boldsymbol{\phi}^{\mathrm{adv}-\mathrm{dif}}\end{array}\right\} \stackrel{\Delta t}{\Rightarrow} \boldsymbol{\phi}^{\mathrm{n}+1}$

The initial condition $I C$ of the advection-diffusion problem (13) is the initial condition $\boldsymbol{\phi}^{n}$ of the full problem, and the solution after a time step $\Delta t$ is $\boldsymbol{\phi}^{\text {adv-dif }}$, which may be regarded as a predicted solution. $O D E(14)$ is then solved by a time $\Delta t$ and with initial condition $\boldsymbol{\phi}^{\text {adv-dif }}$, and the solution of Eq. (14) is then regarded as the approximate solution to the full problem. One may choose the best scheme for each type of sub-problem.

\section{Adopted Taylor-Galerkin Scheme for Advective- Diffusive Transport}

Concerning the advective-diffusion part, the scheme used in this work is a two-step Taylor-Galerkin algorithm, introduced in (Donea 1984; Löhner et al. 1984), and applied to both fluid dynamics and solid mechanics (Mabssout and Pastor 2003a, 2003b; Peraire et al. 1986; Quecedo and Pastor 2002). The method is based on a Taylor expansion in time of the solution at time step $n$,

$\boldsymbol{\phi}^{n+1 / 2}=\boldsymbol{\phi}^{n}+\left.\frac{\Delta t}{2} \frac{\partial \boldsymbol{\phi}}{\partial t}\right|^{n}$

where the time derivative will be evaluated using the $P D E$ as:

$\left.\frac{\partial \boldsymbol{\phi}}{\partial t}\right|^{n}=-\left.\mathbf{Q} \bar{\nabla} \boldsymbol{\phi}\right|^{n}+\left.\mathbf{D} \bar{\nabla}^{2} \boldsymbol{\phi}\right|^{n}$

resulting in:

$\boldsymbol{\phi}^{\mathrm{n}+1 / 2}=\boldsymbol{\phi}^{\mathrm{n}}+\frac{\Delta t}{2}\left(-\left.\mathbf{Q} \bar{\nabla} \boldsymbol{\phi}\right|^{n}+\left.\mathbf{D} \bar{\nabla}^{2} \boldsymbol{\phi}\right|^{n}\right)$

From here, we can obtain fluxes at time $n+1 / 2$ and use them in the second step:

$\boldsymbol{\phi}^{\mathrm{n}+1}=\boldsymbol{\phi}^{\mathrm{n}}+\left.\Delta t \frac{\partial \boldsymbol{\phi}}{\partial t}\right|^{n+1 / 2}=\boldsymbol{\phi}^{\mathrm{n}}+\Delta t\left(-\left.\mathbf{Q} \bar{\nabla} \boldsymbol{\phi}\right|^{n+1 / 2}+\left.\mathbf{D} \bar{\nabla}^{2} \boldsymbol{\phi}\right|^{n+1 / 2}\right)$

From this point, we apply a standard Boubnov-Galerkin method to perform a discretization in space $\boldsymbol{\phi}=\mathbf{N}_{\phi} \hat{\boldsymbol{\phi}}$, obtaining

$\mathbf{M} \Delta \hat{\boldsymbol{\phi}}=\Delta t\left(\int_{\Omega}\left(\nabla \mathbf{N}_{\phi}\right)^{T}\left(\mathbf{Q} \boldsymbol{\phi}^{n+1 / 2}-\left.\mathbf{D} \nabla \boldsymbol{\phi}\right|^{n+1 / 2}\right) \mathrm{d} \Omega-\int_{\partial \Omega} \mathbf{N}_{\phi}^{T}\left(\mathbf{Q} \boldsymbol{\phi}^{n+1 / 2}-\left.\mathbf{D} \nabla \boldsymbol{\phi}\right|^{n+1 / 2}\right) \cdot \mathbf{n} \mathrm{d} \Gamma\right)$ 
where $\mathbf{M}=\int_{\Omega} \mathbf{N}_{\phi}^{T} \mathbf{N}_{\phi} \mathrm{d} \Omega$ is the classical mass matrix and $\Delta \hat{\boldsymbol{\phi}}=\boldsymbol{\phi}^{n+1}-\boldsymbol{\phi}^{n}$. It is important to remark that the system of equations can be written in the form

$\mathbf{M x}=\mathbf{f}$

and can be solved using an iterative Jacobi or "accelerated viscous relaxation scheme". Both are described in (Zienkiewicz and Taylor 2000). The iterations are:

$\mathbf{x}^{(k+1)}=\mathbf{x}^{(k)}+\mathbf{M}_{L}^{-1}\left(\mathbf{f}-\mathbf{M} \mathbf{x}^{(k)}\right)$

where $\mathbf{M}_{L}$ is the lumped mass matrix, which is diagonal. The method can be considered as explicit, and provides an accurate solution in less than 5 iterations.

\section{Adopted Runge-Kutta, Fourth-Order Accurate Scheme for the Source Term}

The second part of the splitting concerns the source term:

$\frac{\mathrm{d} \boldsymbol{\phi}}{\mathrm{d} t}=\mathbf{S}(\boldsymbol{\phi})$

Runge-Kutta $(R K)$ algorithms provide a high accuracy in the evaluation of ODEs (Hirsch 1988; Lambert 1973). The general form of a $R K$ algorithm is

$\boldsymbol{\phi}^{n+1}=\boldsymbol{\phi}^{n}+\Delta t \sum_{k=1}^{k} \beta_{k} \mathbf{S}\left(\boldsymbol{\phi}_{k}\right)$

with

$$
\begin{aligned}
\boldsymbol{\phi}_{1} & =\boldsymbol{\phi}^{n} \\
\boldsymbol{\phi}_{2} & =\boldsymbol{\phi}^{n}+\Delta t \alpha_{2} \mathbf{S}\left(\boldsymbol{\phi}_{1}\right) \\
\boldsymbol{\phi}_{3} & =\boldsymbol{\phi}^{n}+\Delta t \alpha_{3} \mathbf{S}\left(\boldsymbol{\phi}_{2}\right) \\
& \ldots \ldots \ldots \\
\boldsymbol{\phi}_{k} & =\boldsymbol{\phi}^{n}+\Delta t \alpha_{k} \mathbf{S}\left(\boldsymbol{\phi}_{k-1}\right)
\end{aligned}
$$

where the consistency condition $\sum_{k=1}^{k} \beta_{k}=1$ has to be fulfilled.

Here we have chosen a fourth-order $R K$ algorithm, as it provides an excellent combination of accuracy and computational effort. The coefficients are given by:

$\alpha_{2}=\frac{1}{2} ; \quad \alpha_{3}=\frac{1}{2} ; \quad \alpha_{4}=1 ;$

$\beta_{1}=\frac{1}{6} ; \quad \beta_{2}=\beta_{3}=\frac{1}{3} ; \quad \beta_{4}=\frac{1}{6}$;

from where we obtain

$$
\begin{aligned}
\boldsymbol{\phi}_{1} & =\boldsymbol{\phi}^{n} \\
\boldsymbol{\phi}_{2} & =\boldsymbol{\phi}^{n}+\frac{1}{2} \Delta t \mathbf{S}\left(\boldsymbol{\phi}_{1}\right) \\
\boldsymbol{\phi}_{3} & =\boldsymbol{\phi}^{n}+\frac{1}{2} \Delta t \mathbf{S}\left(\boldsymbol{\phi}_{2}\right) \\
\boldsymbol{\phi}_{4} & =\boldsymbol{\phi}^{n}+\Delta t \mathbf{S}\left(\boldsymbol{\phi}_{3}\right) \\
\boldsymbol{\phi}^{n+1} & =\boldsymbol{\phi}^{n}+\frac{\Delta t}{6}\left[\mathbf{S}\left(\boldsymbol{\phi}_{1}\right)+2 \mathbf{S}\left(\boldsymbol{\phi}_{2}\right)+2 \mathbf{S}\left(\boldsymbol{\phi}_{3}\right)+\mathbf{S}\left(\boldsymbol{\phi}_{4}\right)\right]
\end{aligned}
$$

As $\mathbf{S}(\boldsymbol{\phi})=\boldsymbol{\Gamma} \cdot \boldsymbol{\phi}$ with $\boldsymbol{\Gamma}$ constant:

$\boldsymbol{\phi}^{n+1}=\left[1+\Delta t \boldsymbol{\Gamma}+\frac{(\Delta t \boldsymbol{\Gamma})^{2}}{2}+\frac{(\Delta t \boldsymbol{\Gamma})^{3}}{6}+\frac{(\Delta t \boldsymbol{\Gamma})^{4}}{24}\right] \boldsymbol{\phi}^{n}$

\section{Appendix 2}

As described in Ciantia and di Prisco (2015) the two driving variables of weathering of calcarenite are the normalized dissolved mass $\xi_{\text {dis }}$ and the degree of saturation $S_{\mathrm{r}} \xi_{\text {dis }}$, is the dissolution reaction progress variable calculated as

$\xi_{\text {dis }}=\frac{\Delta M}{M_{0}}=\frac{\left[\mathrm{CaCO}_{3}\right]_{0}-\left[\mathrm{CaCO}_{3}\right]}{\left[\mathrm{CaCO}_{3}\right]_{0}}$

where $\Delta M$ and $M_{0}$ are calcium carbonate's dissolved and initial mass, respectively. The weathering function $Y$ governs the size of the yield locus when the material is subject to environmental loads and is a scalar that goes from 1 (intact) to 0 (completely weathered) and can be written as:

$Y=Y_{\text {sus }}+Y_{\text {dis }}$

where

$Y_{\text {sus }}= \begin{cases}\frac{\sigma_{\mathrm{co}}^{\mathrm{d}}-\sigma_{\mathrm{c} 0}^{\mathrm{w}}}{\sigma_{\mathrm{c} 0}^{\mathrm{d}}}\left(1-\frac{S_{\mathrm{r}}}{S_{\mathrm{r}, \mathrm{rr}}}\right)^{2} & S_{\mathrm{r}} \leq S_{\mathrm{r}, \mathrm{cr}} \\ 0 & S_{\mathrm{r}}>S_{\mathrm{r}, \mathrm{cr}}\end{cases}$

$Y_{\text {dis }}= \begin{cases}\frac{\sigma_{c}^{\mathrm{w}}}{\sigma_{\mathrm{co}}^{\mathrm{d}}}\left(1-\frac{\xi_{\mathrm{dis}}}{\xi_{\mathrm{dis}, \mathrm{cr}}}\right)^{2} & \xi_{\mathrm{dis}} \leq \xi_{\mathrm{dis}, \mathrm{cr}} \\ 0 & \xi_{\mathrm{dis}}>\xi_{\mathrm{dis}, \mathrm{cr}}\end{cases}$

While the stiffness weathering function, $Y_{E}$, governs the stiffness of the material when subject to environmental loads and results:

$Y_{E}=Y_{E, \text { sus }}+Y_{E, \text { dis }}$

where

$Y_{E, \text { sus }}= \begin{cases}\frac{E_{0}^{\mathrm{d}}-E_{0}^{\mathrm{w}}}{E_{0}^{\mathrm{d}}}\left(1-\frac{S_{\mathrm{r}}}{S_{\mathrm{r}, \mathrm{cr}}}\right)^{2} & S_{\mathrm{r}} \leq S_{\mathrm{r}, \mathrm{cr}} \\ 0 & S_{\mathrm{r}}>S_{\mathrm{r}, \mathrm{cr}}\end{cases}$ 
$Y_{E, \mathrm{dis}}= \begin{cases}\frac{E_{0}^{\mathrm{w}}}{E_{0}^{\mathrm{d}}}\left(1-\frac{\xi_{\mathrm{dis}}}{\xi_{\mathrm{dis}, \mathrm{cr}}}\right)^{2} & \xi_{\mathrm{dis}} \leq \xi_{\mathrm{dis}, \mathrm{cr}} \\ 0 & \xi_{\mathrm{dis}}>\xi_{\mathrm{dis}, \mathrm{cr}}\end{cases}$

In Eqs. (28)-(32), $\sigma_{\mathrm{c} 0}^{\mathrm{w}}$ and $\sigma_{\mathrm{c} 0}^{\mathrm{d}}$ represent the uniaxial compression strengths of calcarenite rock under wet and dry conditions, respectively; $E_{0}^{\mathrm{d}}$ and $E_{0}^{\mathrm{w}}$ are the Young's moduli of the intact material in dry and wet states, respectively; $S_{\mathrm{r}, \mathrm{cr}}$ is the minimum degree of saturation necessary for all the depositional bonds to suspend, while $\xi_{\text {dis,cr }}$ is the normalized dissolved mass that corresponds to the ideal threshold between the bonded and the granular material state (all bonds have been dissolved).

\section{References}

Alonso EE, Gens A, Josa A (1990) A constitutive model for partially saturated soils. Géotechnique 40:405-430

Boscardin MD, Cording EJ (1989) Building response to excavationinduced settlement. J Geotech Eng 115:1-21

Burland JB (1995) Assessment of risk of damage to buildings due to tunnelling and excavation: Invited special lecture. In: Proceedings of the 1st international conference on earthquake geotechnical engineering. Balkema, Rotterdam, Tokyo, pp 1189-1201

Burland JB, Wroth CP (1974) Settlement of buildings and associated damage. Pentech Press, London, pp 611-654

Castellanza R, Nova R (2004) Oedometric tests on artificially weathered carbonatic soft rocks. J Geotech Geoenviron Eng 130:728-739

Castellanza R, Gerolymatou E, Nova R (2008) An attempt to predict the failure time of abandoned mine pillars. Rock Mech Rock Eng 41:377-401

Castellanza R, Nova R, Orlandi G (2010) Evaluation and remediation of an abandoned gypsum mine. J Geotech Geoenviron Eng 136:629-639

Cekerevac C, Laloui L (2004) Experimental study of thermal effects on the mechanical behaviour of a clay. Int J Numer Anal Methods Geomech 28:209-228

Chang L, Hanssen RF (2014) Detection of cavity migration and sinkhole risk using radar interferometric time series. Remote Sens Environ 147:56-64

Ciantia MO (2013) Multiscale hydro-chemo-mechanical modelling of the weathering of calcareous rocks: an experimental, theoretical and numerical study. Politecnico di Milano

Ciantia MO, di Prisco C (2015) Extension of plasticity theory to debonding, grain dissolution, and chemical damage of calcarenites. Int J Numer Anal Methods Geomech 40:315-343

Ciantia MO, Hueckel T (2013) Weathering of submerged stressed calcarenites: chemo-mechanical coupling mechanisms. Géotechnique 63:768-785

Ciantia MO, Castellanza R, Crosta GB, Hueckel T (2015a) Effects of mineral suspension and dissolution on strength and compressibility of soft carbonate rocks. Eng Geol 184:1-18

Ciantia MO, Castellanza R, di Prisco C (2015b) Experimental study on the water-induced weakening of calcarenites. Rock Mech Rock Eng 48:441-461

Ciantia MO, Castellanza R, di Prisco C, Lollino P, Merodo JAF, Frigerio G (2015c) Evaluation of the stability of underground cavities in calcarenite interacting with buildings using numerical analysis. In: Engineering geology for society and territory, vol 8. Springer International Publishing, Cham, pp 65-69
Conte E, Silvestri F, Troncone A (2010) Stability analysis of slopes in soils with strain-softening behaviour. Comput Geotech $37: 710-722$

De Giorgi L, Leucci G (2014) Detection of hazardous cavities below a road using combined geophysical methods. Surv Geophys 35:1003-1021

Della Vecchia G, Romero E (2013) A fully coupled elastic-plastic hydromechanical model for compacted soils accounting for clay activity. Int J Numer Anal Methods Geomech 37:503-535

Delle Rose M (2007) La voragine di gallipoli e le attività di protezione civile dell'IRPI-CNR. Geol Territ 1:3-12

Di Prisco C, Matiotti R, Nova R (1992) A mathematical model of grouted sand behaviour. In: Pande G, Pietrusczczak S (eds) NUMOG IV. Balkema, Rotterdam, pp 25-35

Donea J (1984) A Taylor-Galerkin method for convective transport problems. Int J Numer Methods Eng 20:101-119

EC7-BSI, 2004. Eurocode 7: Geotechnical design - Part 1: General rules, BS EN 1997-1:2004

Fazio NL, Perrotti M, Lollino P, Parise M, Vattano M, Madonia G, Di Maggio C (2017) A three-dimensional back-analysis of the collapse of an underground cavity in soft rocks. Eng Geol 228:301-311

Fernandez-Merodo JA, Castellanza R, Mabssout M, Pastor M, Nova R, Parma M (2007) Coupling transport of chemical species and damage of bonded geomaterials. Comput Geotech 34:200-215

Franzius JN, Potts DM, Burland JB (2006) The response of surface structures to tunnel construction. Proc Inst Civ Eng Geotech Eng 159:3-17

Gajo A, Cecinato F, Hueckel T (2015) A micro-scale inspired chemomechanical model of bonded geomaterials. Int J Rock Mech Min Sci 80:425-438

Gens A (2010) Soil-environment interactions in geotechnical engineering. Géotechnique 60:3-74

Geomechanica Inc, 2016. Irazu software, v 2.0

Ghabezloo S, Pouya A (2006) Numerical modelling of the effect of weathering on the progressive failure of underground limestone mines. In: Van Cotthem A, Charlier R, Thimus J-F, Tshibangu J-P (eds) EUROCK 2006 - Multiphysics coupling and long term behaviour in rock mechanics. Taylor and Francis Group, London, pp 233-240

Griffiths DV, Fenton GA (2004) Probabilistic slope stability analysis by finite elements. J Geotech Geoenviron Eng 130:507-518

Griffiths DV, Fenton GA, Lemons CB (2002) Probabilistic analysis of underground pillar stability. Int J Numer Anal Methods Geomech 26:775-791

Gutiérrez F, Cooper AH, Johnson KS (2008) Identification, prediction, and mitigation of sinkhole hazards in evaporite karst areas. Environ Geol 53:1007-1022

Hirsch C (1988) Numerical computation of internal and external flows: The fundamentals of computational fluid dynamics, vol 1. Wiley, New York

Hueckel T, Borsetto M (1990) Thermoplasticity of saturated soils and shales: constitutive equations. J Geotech Eng 116:1765-1777

Hueckel T, Ciantia M, Mielniczuk B, El Youssouffi MS, Hu LB (2017) Modeling physico-chemical degradation of mechanical properties to assess resilience of geomaterials. Springer, Cham, pp 65-79

Intrieri E, Gigli G, Nocentini M, Lombardi L, Mugnai F, Fidolini F, Casagli N (2015) Sinkhole monitoring and early warning: an experimental and successful GB-InSAR application. Geomorphology 241:304-314

Istituzione dell'Autorità di bacino della Puglia (2002) LEGGE REGIONALE 9 DICEMBRE 2002, n. 19 [WWW Document]. URL http://www.adb.puglia.it/public/download.php?view.251

Istituzione dell'Autorità di bacino della Puglia (2006) Atto di indirizzo per la messa in sicurezza dei Territori a rischio cavita' sotterranee 
[WWW Document]. URL http://www.adb.puglia.it/public/downl oad.php?view. 258

Jommi C (2000) Remarks on the constitutive modelling of unsaturated soils. Exp. Evid. Theor. approaches unsaturated soils, pp 139-153

Jones CE, Blom RG (2014) Bayou Corne, Louisiana, sinkhole: precursory deformation measured by radar interferometry. Geology 42:111-114

Knappett J, Craig RF (2012) Craig's soil mechanics. Spon Press, London

Lagioia R, Nova R (1995) An experimental and theoretical study of the behaviour of a calcarenite in triaxial compression. Géotechnique 45:633-648

Lambert JD (1973) Computational methods in ordinary differential equations. Wiley, London

Leucci G, Negri S, Carrozzo MT, Nuzzo L (2002) Use of ground penetrating radar to map subsurface moisture variations in an urban area. J Environ Eng Geophys 7:69-77

Löhner R, Morgan K, Zienkiewicz OC (1984) The solution of nonlinear hyperbolic equation systems by the finite element method. Int J Numer Methods Fluids 4:1043-1063

Lollino P, Andriani GF (2017) Role of brittle behaviour of soft calcarenites under low confinement: laboratory observations and numerical investigation. Rock Mech Rock Eng 50:1863-1882

Lollino P, Martimucci V, Parise M (2013) Geological survey and numerical modeling of the potential failure mechanisms of underground caves. Geosystem Eng 16:100-112

Lumb P (1962) The properties of decomposed granite. Géotechnique $12: 226-243$

Mabssout M, Pastor M (2003a) A Taylor-Galerkin algorithm for shock wave propagation and strain localization failure of viscoplastic continua. Comput Methods Appl Mech Eng 192:955-971

Mabssout M, Pastor M (2003b) A two-step Taylor-Galerkin algorithm applied to shock wave propagation in soils. Int J Numer Anal Methods Geomech 27:685-704

Nof RN, Baer G, Ziv A, Raz E, Atzori S, Salvi S (2013) Sinkhole precursors along the Dead Sea, Israel, revealed by SAR interferometry. Geology 41:1019-1022

Nova R (1992) Mathematical modelling of natural and engineered geomaterials. Eur J Mech A Solids 11:135-154

Nova R (1997) On the modelling of the mechanical effects of diagenesis and weathering. ISRM News J 4:15-20

Nova R, Parma M (2011) Effects of bond crushing on the settlements of shallow foundations on soft rocks. Géotechnique 61:247-261

Nova R, Castellanza R, Tamagnini C (2003) A constitutive model for bonded geomaterials subject to mechanical and/or chemical degradation. Int J Numer Anal Methods Geomech 27:705-732

Parise M, Lollino P (2011) A preliminary analysis of failure mechanisms in karst and man-made underground caves in Southern Italy. Geomorphology 134:132-143

Parise M, Vennari C (2017) Distribution and features of natural and anthropogenic sinkholes in Apulia. Springer, Berlin, pp 27-34

Peck RB (1969) Deep excavations and tunnelling in soft ground. State-of-the-Art Report. In: Proceedings of 7th ICSMFE, Mexico, pp 225-290
Peraire J, Zienkiewicz OC, Morgan K (1986) Shallow water problems: a general explicit formulation. Int J Numer Methods Eng $22: 547-574$

Polimeno A (2007) Il crollo di via Firenze in Gallipoli. l'intervento dei vigili del fuoco, Geologi e Territorio, 4-2006/1-2007, 13-19 (in Italian)

Potts DM, Addenbrooke TI (1997) A structure's influence on tunnelling-induced ground movements. Proc Inst Civ Eng Geotech Eng 125:109-125

Potts DM, Dounias GT, Vaughan PR (1990) Finite element analysis of progressive failure of Carsington embankment. Géotechnique 40:79-101

Quecedo M, Pastor M (2002) A reappraisal of Taylor-Galerkin algorithm for drying-wetting areas in shallow water computations. Int J Numer Methods Fluids 38:515-531

Rodriguez JM, Carbonell JM, Cante JC, Oliver J (2016) The particle finite element method (PFEM) in thermo-mechanical problems. Int J Numer Methods Eng 107:733-785

Rutter EH, Elliott D (1976) The kinetics of rock deformation by pressure solution [and discussion]. Philos Trans R Soc A Math Phys Eng Sci 283:203-219

Son M, Cording EJ (2005) Estimation of building damage due to excavation-induced ground movements. J Geotech Geoenviron Eng 131:162-177

Sowers GF (1996) Building on sinkholes. American Society of Civil Engineers, New York

Tamagnini C, Ciantia MO (2016) Plasticity with generalized hardening: constitutive modeling and computational aspects. Acta Geotech 11:595-623

Tamagnini C, Castellanza R, Nova R (2002) A Generalized Backward Euler algorithm for the numerical integration of an isotropic hardening elastoplastic model for mechanical and chemical degradation of bonded geomaterials. Int J Numer Anal Methods Geomech 26:963-1004

Toro EF (2001) Shock-capturing methods for free-surface shallow flows. Wiley, New York

Uchaipichat A, Khalili N (2009) Experimental investigation of thermohydro-mechanical behaviour of an unsaturated silt. Géotechnique 59:339-353

Zhang LM, Ng AMY (2005) Probabilistic limiting tolerable displacements for serviceability limit state design of foundations. Géotechnique 55:151-161

Zheng CM, Bennett GD (2002) Applied contaminant transport modelling. Wiley-Interscience, New York

Zienkiewicz OC, Shiomi T (1984) Dynamic behaviour of saturated porous media; The generalized Biot formulation and its numerical solution. Int J Numer Anal Methods Geomech 8:71-96

Zienkiewicz OC, Taylor RL (2000) The finite element method, 5th edn. Butterworth, Oxford

Publisher's Note Springer Nature remains neutral with regard to jurisdictional claims in published maps and institutional affiliations. 